\title{
GWAS defines pathogenic signaling pathways and prioritizes drug targets for IgA nephropathy
}

Krzysztof Kiryluk ${ }^{1,2 \wedge}$, Elena Sanchez-Rodriguez ${ }^{1 *}$, Xu-jie Zhou ${ }^{3 *}$, Francesca Zanoni ${ }^{l}$, Lili Liu ${ }^{l}$, Nikol Mladkoval, Atlas Khan ${ }^{l}$, Maddalena Marasa, ${ }^{,}$, Jun Y. Zhang ${ }^{l}$, Olivia Balderes ${ }^{l}$, Simone Sanna-Cherchi ${ }^{1,2}$, Andrew S. Bomback ${ }^{l}$, Pietro A. Canettal, Gerald B. Appel ${ }^{1}$, Jai Radhakrishnan ${ }^{1}$, Hernan Trimarchi ${ }^{4}$, Ben Sprangers ${ }^{5,6}$, Daniel C. Cattran ${ }^{7}$, Heather Reich ${ }^{7}$, York Pei ${ }^{7}$, Pietro Ravani ${ }^{8}$, Kresimir Galesic ${ }^{9}$, Dita Maixnerova ${ }^{10}$, Vladimir Tesar $^{10}$, Benedicte Stengel ${ }^{11}$, Marie Metzger ${ }^{11}$, Guillaume Canaud $^{12}$, Nicolas Maillard ${ }^{13}$, Francois Berthoux ${ }^{13}$, Laureline Berthelot ${ }^{14}$, Evangeline Pillebout ${ }^{15}$, Renato Monteiro ${ }^{15}$, Raoul Nelson $^{16}$, Robert Wyatt ${ }^{17,18}$, William Smoyer ${ }^{19}$, John Mahan ${ }^{19}$, Al-Akash Samhar ${ }^{20}$, Guillermo Hidalgo ${ }^{21}$, Alejandro Quiroga ${ }^{22}$, Patricia Weng ${ }^{23}$, Raji Sreedharan ${ }^{24}$, David Selewski ${ }^{25}$, Keefe Davis ${ }^{26}$, Mahmoud Kallash ${ }^{27}$, Tetyana L. Vasylyeva ${ }^{28}$, Michelle Rheault $^{29}$, Aftab Chishti ${ }^{30}$, Daniel Ranch ${ }^{31}$, Scott E. Wenderfer ${ }^{32}$, Dmitry Samsonov ${ }^{33}$, Donna J. Claes ${ }^{34}$, Akchurin Oleh ${ }^{35}$, Dimitrios Goumenos $^{36}$, Maria Stangou ${ }^{36}$, Judit Nagy ${ }^{37}$, Tibor Kovacs ${ }^{37}$, Enrico Fiaccadori ${ }^{38}$, Antonio Amoroso ${ }^{39}$, Cristina Barlassina ${ }^{40}$, Daniele Cusi ${ }^{40}$, Lucia Del Vecchio ${ }^{41}$, Giovanni Giorgio Battaglia ${ }^{42}$, Monica Bodria ${ }^{43}$, Emanuela Boer ${ }^{44}$, Luisa Bono $^{45}$, Giuliano Boscutti ${ }^{46}$, Gianluca Caridi ${ }^{47}$, Francesca Lugani ${ }^{48}$, GianMarco Ghiggeri ${ }^{47}$, Rosanna Coppo ${ }^{48}$, Licia Peruzzi $^{48}$, Vittoria Esposito ${ }^{49}$, Ciro Esposito ${ }^{49}$, Sandro Feriozzi ${ }^{50}$, Rosaria Polci ${ }^{50}$, Giovanni Frasca ${ }^{51}$, Marco Galliani ${ }^{52}$, Maurizio Garozzo ${ }^{53}$, Adele Mitrotti ${ }^{54}$, Loreto Gesualdo ${ }^{54}$, Simona Granata ${ }^{55}$, Gianluigi Zaza ${ }^{55}$, Francesco Londrino ${ }^{56}$, Riccardo Magistroni ${ }^{57}$, Isabella Pisani ${ }^{58}$, Andrea Magnano ${ }^{58}$, Carmelita Marcantoni ${ }^{59}$, Piergiorgio Messa ${ }^{60}$, Renzo Mignani ${ }^{61}$, Antonello Pani ${ }^{62}$, Claudio Ponticelli ${ }^{63}$, Dario Roccatello ${ }^{64}$, Maurizio Salvadori ${ }^{65}$, Erica Salvi ${ }^{66}$, Domenico Santoro ${ }^{67}$, Guido Gembillo $^{67}$, Silvana Savoldi ${ }^{68}$, Donatella Spotti ${ }^{69}$, Pasquale Zamboli ${ }^{70}$, Claudia Izzi $^{71}$, Federico Alberici ${ }^{71}$, Elisa Delbarba ${ }^{71}$, Michat Florczak ${ }^{72}$, Natalia Krata ${ }^{72}$, Krzysztof Mucha ${ }^{72,73}$, Leszek Paczek ${ }^{72,73}$, Stanistaw Niemczyk ${ }^{74}$, Barbara Moszczuk ${ }^{72,75}$, Malgorzata Pańczyk-Tomaszewska ${ }^{76}$, Malgorzata Mizerska-Wasiak ${ }^{76}$, Agnieszka Perkowska-Ptasińska ${ }^{77}$, Teresa Baczkowska ${ }^{78}$, Magdalena Durlik ${ }^{78}$, Krzysztof Pawlaczyk ${ }^{79}$, Przemyslaw Sikora ${ }^{80}$, Marcin Zaniew ${ }^{81}$, Dorota Kaminska ${ }^{82}$, Magdalena Krajewska $^{82}$, Izabella Kuzmiuk-Glembin ${ }^{83}$, Zbigniew Heleniak ${ }^{83}$, Barbara Bullo-Piontecka ${ }^{83}$, Tomasz Liberek ${ }^{83}$, Alicja DębskaSlizien $^{83}$, Tomasz Hryszko ${ }^{84}$, Anna Materna-Kiryluk ${ }^{85}$, Monika Miklaszewska ${ }^{86}$, Maria Szczepańska ${ }^{87}$, Katarzyna Dyga ${ }^{87}$, Edyta Machura $^{87}$, Katarzyna Siniewicz-Luzeńczyk ${ }^{88}$, Monika Pawlak-Bratkowska ${ }^{88}$, Marcin Tkaczyk ${ }^{88}$, Dariusz Runowski ${ }^{89}$, Norbert Kwella $^{90}$, Dorota Drożdż ${ }^{91}$, Ireneusz Habura ${ }^{92}$, Florian Kronenberg ${ }^{93}$, Larisa Prikhodina ${ }^{94}$, David van Heel ${ }^{95}$, Bertrand

Fontaine $^{96,97}$, Chris Cotsapas ${ }^{98}$, Cisca Wijmenga ${ }^{99}$, Andre Franke ${ }^{100}$, Vito Annese ${ }^{101}$, Peter K. Gregersen ${ }^{102}$, Sreeja Parameswaran $^{103}$, Matthew Weirauch ${ }^{103,104}$, Leah Kottyan ${ }^{103,104}$, John B Harley ${ }^{105}$, Hitoshi Suzuki ${ }^{106}$, Ichiei Narita ${ }^{107}$, Shin Goto $^{107}$, Hajeong Lee ${ }^{108}$, Dong Ki Kim ${ }^{108}$, Yon Su Kim ${ }^{109}$, Jin-Ho Park ${ }^{110}$, BeLong Cho ${ }^{110,111}$, Murim Choi ${ }^{109}$, Ans Van Wijk ${ }^{112}$, Ana Huertal13, Elisabet Ars ${ }^{14}$, Jose Ballarin ${ }^{114}$, Sigrid Lundberg ${ }^{115}$, Bruno Vogt ${ }^{116}$, Laila-Yasmin Mani ${ }^{116}$, Yasar Caliskan ${ }^{117}$, Jonathan Barratt ${ }^{118}$, Thilini Abeygunaratne ${ }^{119}$, Philip A. Kalra ${ }^{19}$, Daniel P. Gale ${ }^{120}$, Ulf Panzer ${ }^{121}$, Thomas Rauen ${ }^{122}$, Jürgen Floege $^{122}$, Pascal Schlosser ${ }^{123}$, Arif B. Ekici ${ }^{124}$, Kai-Uwe Eckardt ${ }^{125,126}$, Nan Chen ${ }^{127}$, Jingyuan Xie ${ }^{127}$, Richard P. Lifton ${ }^{128,129}$, Ruth J. F. Loos ${ }^{130,131}$, Eimear E. Kenny ${ }^{130,132,133}$, Iuliana Ionita-Laza ${ }^{134}$, Anna Köttgen ${ }^{123}$, Bruce Julian ${ }^{135}$, Jan Novak ${ }^{135}$, Francesco Scolari ${ }^{71}$, Hong Zhang ${ }^{3}$, Ali G. Gharavil,2^.

\section{Affiliations:}

1. Department of Medicine, Vagelos College of Physicians \& Surgeons, Columbia University, New York, New York, USA

2. Institute for Genomic Medicine, Columbia University, New York, New York, USA

3. Renal Division, Peking University First Hospital, Peking University Institute of Nephrology, Beijing, China

4. Nephrology Service, Hospital Británico de Buenos Aires, Perdriel 74 (1280), Buenos Aires, Argentina.

5. Department of Microbiology and Immunology, Laboratory of Molecular Immunology, KU Leuven, Leuven, Belgium

6. Division of Nephrology, University Hospitals Leuven, Leuven, Belgium

7. Department of Nephrology, University of Toronto, Toronto General Hospital, Toronto, Ontario, Cananda.

8. Division of Nephrology, Department of Internal Medicine, University of Calgary, Calgary, Canada

9. Zagreb Medical School, Zagreb, Croatia

10. 1st Faculty of Medicine and General University Hospital,Charles University, Prague, Czech Republic

11. Centre for Research in Epidemiology and Population Health (CESP), Paris-Saclay University, Versailles Saint Quentin University, Inserm, Clinical Epidemiology Team, Villejuif, France

12. Université de Paris, Hôpital Necker-Enfants Malades, INSERM U1151, Paris, France

13. Nephrology, Dialysis, and Renal Transplantation Department, University North Hospital, Saint Etienne, France

14. CRTI UMR1064, Inserm, Nantes University, Nantes, France

15. Center for Research on Inflammation, University of Paris, Inserm U1149 \& Cnrs ERL8252, Paris, France

16. Division of Pediatric Nephrology, Department of Pediatrics, University of Utah, USA

17. Division of Pediatric Nephrology, University of Tennessee Health Sciences Center, Memphis, Tennessee, USA

18. Children's Foundation Research Center, Le Bonheur Children's Hospital, Memphis, Tennessee, USA

NOTE: This preprint reports new research that has not been certified by peer review and should not be used to guide clinical practice. 
It is made available under a CC-BY-NC-ND 4.0 International license .

19. Division of Pediatric Nephrology, Nationwide Children's Hospital, USA

20. Division of Pediatric Nephrology, Driscoll Children's Hospital, USA

21. Division of Pediatric Nephrology, Department of Pediatrics, HMH Hackensack University Medical Center, New Jersey, USA

22. Division of Pediatric Nephrology, Mattel Children's Hospital, USA

23. Division of Pediatric Nephrology, Medical College of Wisconsin, USA

24. Division of Pediatric Nephrology, Mott Children's Hospital, USA

25. Division of Pediatric Nephrology, Department of Pediatrics, the Medical University of South Carolina (MUSC), South Caroline, USA

26. Division of Pediatric Nephrology, SUNY Buffalo, USA

27. Division of Pediatric Nephrology, Department of Pediatrics, Nationwide Children's Hospital, OH, USA

28. Division of Pediatric Nephrology, University of Minnesota, USA

29. Division of Pediatric Nephrology, University of Kentucky, USA

30. Division of Pediatric Nephrology, Department of Pediatrics, University of Kentucky, USA

31. Division of Pediatric Nephrology, Baylor College of Medicine/Texas Children's Hospital, USA

32. Division of Pediatric Nephrology, Boston Children's Hospital, USA

33. Division of Pediatric Nephrology, Department of Pediatrics, New York Medical College, NY, USA

34. Division of Pediatric Nephrology, Cornell University, USA

35. The Aristotle University of Thessaloniki, Greece

36. 2nd Department of Internal Medicine, Nephrological and Diabetological Center, University of Pécs, Hungary

37. Department of Medicine and Surgery, University of Parma, Parma, Italy.

38. Department of Medical Sciences, University of Turin, Italy

39. Renal Division, Dipartimento di Medicina, Chirurgia e Odontoiatria, San Paolo Hospital, School of Medicine, University of Milan, Milan, Italy

40. Department of Nephrology and dialysis, ASST Lariana, Como, Italy

41. Unità Operativa di Nefrologia e Dialisi, Ospedale di Acireale, Acireale, Italy

42. University of Messina, Italy

43. Division of Nephrology and Dialysis, Gorizia Hospital, Gorizia, Italy

44. Nephrology and Dialysis, A.R.N.A.S. Civico and Benfratellio, Palermo, Italy

45. Nephrology, Dialysis and Renal Transplant Unit, S. Maria della Misericordia Hospital, ASUFC Udine, Italy

46. Division of Nephrology, Dialysis and Transplantation, IRCCS Giannina Gaslini Institute, Genova, Italy

47. Regina Margherita Children's Hospital, Torino, Italy

48. ICS Maugeri SpA, University of Pavia, Italy

49. Belcolle Hospital, Viterbo, Italy

50. Division of Nephrology, Dialysis and Renal Transplantation, Riuniti Hospital, Ancona, Italy

51. Sandro Pertini Hospital, Rome, Italy;

52. Unità Operativa di Nefrologia e Dialisi, Ospedale di Acireale, Acireale, Italy

53. Nephrology, Dialysis and Transplantation Unit, Department of Emergency and Organ Transplantation, University of Bari Aldo Moro, Bari, Italy

54. Renal Unit, Department of Medicine, University of Verona, Italy

55. S. Andrea Hospital, La Spezia, Italy

56. Department of Surgical, Medical, Dental, Oncologic and Regenerative Medicine, University of Modena and Reggio Emilia

57. Department of Medicine and Surgery, University of Parma, Italy

58. Nephrology Division, San Marco Hospital, Catania, Italy

59. Nephrology Dialysis and Kidney Transplant Unit, Fundazione IRCCS Ca' Granda Ospedale Maggiore Policlinico, Università degli studi di Milano, Milan, Italy

60. Azienda Unità Sanitaria Locale Rimini, Italy

61. Department of Nephrology and Dialysis, G. Brotzu Hospital, Cagliari, Italy

62. Nephrology and Dialysis, Ospedale Maggiore, Milano,Italy (retired)

63. Nephrology and Dialysis Unit, G. Bosco Hub Hospital (ERK-net Member) and University of Torino, Italy

64. Division of Nephrology and Renal Transplantation, Carreggi Hospital, Florence, Italy

65. Renal Division, DMCO (Dipartimento di Medicina, Chirurgia e Odontoiatria), San Paolo Hospital, School of Medicine, University of Milan, Milan, Italy

66. Unit of Nephrology and Dialysis, AOU G Martino, University of Messina, Italy

67. Unit of Nephrology and Dialysis ASL TO4, Cirié, Turin, Italy

68. San Raffaele Hospital, Milan, Italy

69. NephroCare Italy, Naples, Italy

70. Department of Medical and Surgical Specialties and Nephrology Unit, University of Brescia - ASST Spedali Civili, Brescia, Italy

71. Department of Immunology, Transplantology and Internal Diseases, Medical University of Warsaw, Poland

72. Institute of Biochemistry and Biophysics, Polish Academy of Sciences, Warsaw, Poland

73. Department of Internal Disease, Nephrology and Dialysotherapy, Military Institute of Medicine, Warsaw, Poland

74. Department of Clinical Immunology, Medical University of Warsaw, Warsaw, Poland

75. Department of Pediatrics and Nephrology, Medical University of Warsaw, Warsaw, Poland

76. Department of Pathology, Medical University of Warsaw, Poland

77. Department of Transplantation Medicine, Nephrology and Internal Diseases, Medical University of Warsaw, Poland

78. Department of Nephrology, Transplantology and Internal Medicine, Poznan Medical University, Poznan, Poland

79. Department of Pediatric Nephrology Medical University of Lublin, Poland

80. Department of Pediatrics, University of Zielona Góra, Zielona Góra, Poland

81. Clinical Department of Nephrology and Transplantation Medicine, Wroclaw Medical University, Wroclaw, Poland

82. Department of Nephrology, Transplantology and Internal Diseases, Medical University of Gdansk, Poland

83. 2nd Department of Nephrology and Hypertension with Dialysis Unit, Medical University of Bialystok, Poland

84. Department of Genetics, Medical University of Poznan, Poznan, Poland

85. Department of Pediatric Nephrology and Hypertension, Jagiellonian University Medical College, Krakow, Poland

86. Department of Pediatrics, Faculty of Medical Sciences in Zabrze, Medical University of Silesia in Katowice, Poland

87. Department of Pediatrics, Immunology and Nephrology, Polish Mother's Memorial Hospital Research Institute, Lodz, Poland

88. Department of Nephrology, Kidney Transplantation and Hypertension, Children's Memorial Health Institute, Warsaw, Poland

89. Department of Nephrology, Hypertension and Internal Medicine, University of Warmia and Mazury in Olsztyn, Olsztyn, Poland

90. Department of Pediatric Nephrology and Hypertension, Jagiellonian University Medical College, Krakow

91. Department of Nephrology, Karol Marcinkowski Hospital, Zielona Góra, Poland

92. Institute of Genetic Epidemiology, Department of Genetics and Pharmacology, Medical University of Innsbruck, Innsbruck, Austria. 
93. Division of Inherited \& Acquired Kidney Diseases, Veltischev Research and Clinical Institute for Pediatrics of the Pirogov Russian National Research Medical University, Moscow, Russia

94. Barts and The London School of Medicine and Dentistry, Queen Mary University of London, London, UK

95. Sorbonne University, INSERM. Center of Research in Myology - UMR 974, Institute of Myology, University Hospital Pitie-Salpetriere, Paris, France

96. Assistance Publique-Hôpitaux de Paris (AP-HP), Service of Neuro-Myology, University Hospital Pitie-Salpetriere, Paris, France

97. Departments of Neurology and Genetics, Yale University

98. University of Groningen, Groningen, the Netherlands

99. Institute of Clinical Molecular Biology, Christian-Albrechts-University of Kiel, Kiel, Germany

100. CBP American Hospital, Dubai, United Arab Emirates

101. Robert S. Boas Center for Genomics and Human Genetics, Feinstein Institute for Medical Research, North Shore LIJ Health System, New York, USA

102. Cincinnati Children's Hospital Medical Center, Cincinnati, Ohio, USA

103. University of Cincinnati College of Medicine, Cincinnati, Ohio, USA

104. US Department of Veterans Affairs Medical Center, Cincinnati, OH and Cincinnati Educational and Research for Veterans Foundation, Cincinnati, Ohio, USA

105. Department of Nephrology, Juntendo University Faculty of Medicine, Tokyo, Japan

106. Division of Clinical Nephrology and Rheumatology, Kidney Research Center, Niigata University Graduate School of Medical and Dental Sciences.

107. Internal Medicine, Seoul National University College of Medicine, Seoul, Korea

108. Biomedical Science, Seoul National University College of Medicine, Seoul, Korea

109. Department of Family Medicine, Seoul National University College of Medicine and Seoul National University Hospital, Seoul, Korea

110. Institute on Aging, Seoul National University College of Medicine, Seoul, Korea

111. Amsterdam University Medical Centre, VU University Medical Center (VUMC) location, Amsterdam, Netherlands

112. Hospital Universitario Puerta del Hierro Majadahonda, Spain. REDINREN, IISCIII, Spain.

113. Molecular Biology Laboratory and Nephrology Department, Fundació Puigvert, Instituto de Investigaciones Biomédicas Sant Pau, Universitat Autònoma de Barcelona, REDINREN, IISCIII, Barcelona, Spain

114. Department of Nephrology, Danderyd University Hospital, and Department of Clinical Sciences, Karolinska Institutet, Stockholm, Sweden

115. Department of Nephrology and Hypertension, Inselspital, Bern University Hospital, University of Bern, Bern, Switzerland

116. Division of Nephrology, Saint Louis University, Saint Louis, MO, USA

117. John Walls Renal Unit, University Hospitals of Leicester, Leicester, UK

118. National Institute of Health Research, UK

119. Salford Royal Hospital, Salford, UK

120. University of Hamburg, Germany

121. Division of Nephrology and Clinical Immunology, RWTH Aachen University, Aachen, Germany

122. Institute of Genetic Epidemiology, Faculty of Medicine and Medical Center, University of Freiburg, Freiburg, Germany.

123. Institute of Human Genetics, Friedrich-Alexander-Universität Erlangen-Nürnberg, Erlangen, Germany.

124. Department of Nephrology and Medical Intensive Care, Charité-Universitätsmedizin Berlin, Berlin, Germany.

125. Department of Nephrology and Hypertension, Friedrich-Alexander-Universität Erlangen-Nürnberg, Erlangen, Germany.

126. Department of Nephrology, Ruijin Hospital, Shanghai Jiaotong University School of Medicine, Shanghai, China

127. Department of Genetics, Yale School of Medicine, New Haven, Connecticut, USA

128. Laboratory of Human Genetics and Genomics, The Rockefeller University, New York, New York, USA

129. The Charles Bronfman Institute for Personalized Medicine, Icahn School of Medicine at Mount Sinai, New York, New York, USA

130. Novo Nordisk Foundation Center for Basic Metabolic Research, Department of Health and Medical Sciences, University of Copenhagen, Copenhagen, Denmark

131. Department of Genetics and Genomic Sciences, Mount Sinai Health System, New York, New York, USA

132. Center for Population Genomic Health, Icahn School of Medicine at Mount Sinai, New York, New York, USA

133. Department of Biostatistics, Mailman School of Public Health, Columbia University, New York, USA

134. Departments of Microbiology and Medicine, University of Alabama at Birmingham, Birmingham, Alabama, USA

\section{** Equal contributions \\ $\wedge$ Corresponding Authors:}

Krzysztof Kiryluk, M.D. M.S.

Division of Nephrology, Department of Medicine

Institute for Genomic Medicine

College of Physicians \& Surgeons, Columbia University

1150 St. Nicholas Ave., Russ Berrie Pavilion 412E, New York, NY 10032

kk473@,columbia.edu

Ali G. Gharavi, M.D.

Division of Nephrology, Department of Medicine 
medRxiv preprint doi: https://doi.org/10.1101/2021.11.19.21265383; this version posted November 20, 2021. The copyright holder for this preprint (which was not certified by peer review) is the author/funder, who has granted medRxiv a license to display the preprint in perpetuity. It is made available under a CC-BY-NC-ND 4.0 International license .

\section{ABSTRACT}

$4 \quad \operatorname{IgA}$ nephropathy (IgAN) is a progressive form of kidney disease defined by glomerular deposition of $\operatorname{IgA}$.

5 We performed a genome-wide association study involving 10,146 kidney biopsy-diagnosed IgAN cases and 28,751 matched controls across 17 international cohorts. We defined 30 independent genome-wide significant risk loci jointly explaining $11 \%$ of disease risk. A total of 16 loci were novel, including TNFSF4, REL, CD28, CXCL8/PF4V1, LY86, LYN, ANXA3, TNFSF8/15, REEP3, ZMIZ1, RELA, ETS1, IGH, IRF8, TNFRSF 13B and FCAR. The SNP-based heritability of IgAN was estimated at 23\%. We observed a positive genetic correlation between IgAN and total serum IgA levels, allergy, tonsillectomy, and several infections, and a negative correlation with inflammatory bowel disease. All significant nonHLA loci shared with serum IgA levels had a concordant effect on the risk of IgAN. Moreover, IgAN loci were globally enriched in gene orthologs causing abnormal IgA levels when genetically manipulated in mice. The explained heritability was enriched in the regulatory elements of cells from the immune and hematopoietic systems and intestinal mucosa, providing support for the pathogenic role of extra-renal tissues. The polygenic risk of IgAN was associated with early disease onset, increased lifetime risk of kidney failure, as well as hematuria and several other traits in a phenome-wide association study of 590,515 individuals. In the comprehensive functional annotation analysis of candidate causal genes across genome-wide significant loci, we observed the convergence of biological candidates on a common set of inflammatory signaling pathways and cytokine ligand-receptor pairs, prioritizing potential new drug targets. 
medRxiv preprint doi: https://doi.org/10.1101/2021.11.19.21265383; this version posted November 20, 2021. The copyright holder for this preprint (which was not certified by peer review) is the author/funder, who has granted medRxiv a license to display the preprint in perpetuity.

It is made available under a CC-BY-NC-ND 4.0 International license .

\section{INTRODUCTION}

4 IgA nephropathy (IgAN) is a common form of immune-mediated glomerulonephritis characterized by

5 glomerular deposition of IgA-containing immune complexes and manifesting with hematuria, proteinuria,

6 and often kidney failure. Examination of kidney-biopsy tissue and demonstration of glomerular IgA

7 deposits is required to establish the diagnosis. No approved targeted therapies presently exist for IgAN, and a large fraction of cases progress to kidney failure requiring kidney transplantation or dialysis. There are no validated molecular predictors of progression to kidney failure.

As the diagnosis requires a kidney biopsy, genetic discoveries have been hindered by small sample sizes of the existing genetic cohorts. Approximately 15 independent loci have been previously identified in association with IgAN, implicating defects in the complement pathway, intestinal network of IgA production, and innate immunity against mucosal pathogens ${ }^{1-7}$. These findings have already led to the reformulation of the existing IgAN pathogenesis model, with most candidate mechanisms mapping to the immune system rather than the kidney ${ }^{8,9}$. Nevertheless, prior GWAS had a two-stage design, with sample size of the discovery stage often limiting the power to discover new loci.

Herein, we report a well-powered GWAS discovery study for IgAN involving 38,897 individuals $(10,146$ kidney biopsy-defined cases and 28,751 controls) recruited across 17 international cohorts. With the discovery of 16 novel non-HLA GWAS loci, we provide strong support for a highly polygenic architecture of IgAN. We assess functional consequences of the risk alleles, define causal cell types and signaling pathways, and explore genetic correlations and pleiotropic associations of the risk loci. We demonstrate that IgAN polygenic score predicts kidney disease outcomes. Importantly, we report convergence of multiple risk loci on the set of common signaling pathways and ligand-receptor pairs involved in the regulation of IgA production, prioritizing plausible new molecular drug targets. 


\section{RESULTS}

4

Study Design

We performed a standardized GWAS and meta-analysis of 17 independent international case-control individuals (10,146 biopsy-proven cases and 28,751 controls). Of the 17 cohorts, 11 were of European ancestry with participants recruited from nephrology centers in Italy, Poland, Germany, France, Belgium, Czech Republic, Hungary, Croatia, Turkey, Spain, Sweden, U.K., U.S., Canada, and Argentina, and six cohorts were of East-Asian ancestry with participants recruited from nephrology centers in China, Japan, and Korea. A total of 14 cohorts (8,139 cases and 17,713 controls) were genotyped with high-density SNP arrays, ancestrally matched using principal component-based methods, and imputed using whole genome sequence reference panels specific for each ethnicity, and three additional cohorts $(2,007$ cases and 11,038 controls) were genotyped with the Immunochip platform (Supplementary Table 1).

Detailed description of each cohort, genotyping platform, quality control analysis, and ancestry and imputation analyses are provided as Supplementary Notes. Our primary discovery involved the combined analysis of all 17 cohorts under a log-additive genetic model. Additional exploratory analyses were conducted to identify any potential ancestry-specific and sex-specific locus, including under alternative (dominant and recessive) genetic models.

\section{Genome-wide significant loci}

The results of combined meta-analyses across all cohorts are summarized in Figure 1, Tables 2 and 
medRxiv preprint doi: https://doi.org/10.1101/2021.11.19.21265383; this version posted November 20, 2021. The copyright holder for this preprint (which was not certified by peer review) is the author/funder, who has granted medRxiv a license to display the preprint in perpetuity.

It is made available under a CC-BY-NC-ND 4.0 International license .

2 signals in the HLA region, with an overall $\lambda=1.048$ and 1.042 before and after excluding the HLA region

3 (Extended Data Figure 1). In addition, we detected 24 independently associated non-HLA loci at a

4 genome-wide significance, including eight known non-HLA loci (CFH, DEFA1/4, CARD9,

ITGAM/ITGAX, TNFSF13, LIF/OSM, FCRL3, IRF4/DUSP22), 16 novel loci (TNFSF4, CD28, REL,

PF4V1/CXCL1, LY86/RREB1, LYN, ANXA3, TNFSF8/15, REEP3, ZMIZ1/PPIF, OVOL1/RELA, ETS1,

IGH, IRF8, TNFRSF13B and FCAR, see Extended Data Figure 2), in addition to 48 independent

suggestive non-HLA signals at $P<1 \times 10^{-5}$ (Supplementary Tables 2 and 3). Ethnicity-specific meta-

analyses revealed another independent genome-wide significant association that was evident only in the

East-Asian cohorts (CCR6 locus, Extended Data Figure 3a) and 11 additional suggestive signals in this

ancestral group (Supplementary Table 4). One of the suggestive signals in the combined meta-analysis

(PADI3/PADI4 locus) reached genome-wide significance in the East-Asian meta-analysis under a

recessive model (Extended Data Figure 3b). The European-only meta-analysis showed a total of 19

suggestive signals, but no additional new genome-wide significant loci (Supplementary Table 4). No

gender-specific loci were found in a gender-stratified meta-analysis, or in the analysis of sex

chromosomal markers.

We next performed stepwise conditional analyses of the 24 genome-wide significant non-HLA loci, but only the $C F H$ locus showed evidence of at least two independent genome-wide significant variants

(Supplementary Table 5 and Extended Data Figure 4a). Stepwise conditional analyses of the $H L A$

region revealed a complex pattern of association, with at least five independently genome-wide significant

SNPs in the combined analysis of all cohorts (Extended Data Figure 4b, Supplementary Table 6). In addition, the patterns of association across the HLA region differed when stepwise conditioning was 
medRxiv preprint doi: https://doi.org/10.1101/2021.11.19.21265383; this version posted November 20, 2021. The copyright holder for this preprint (which was not certified by peer review) is the author/funder, who has granted medRxiv a license to display the preprint in perpetuity.

It is made available under a CC-BY-NC-ND 4.0 International license.

2 observed an inverse relationship between minor allelic frequency of the top independently associated

3 variants and their effect sizes, consistent with the effects of purifying selection (Figure 1b).

4 Based on genome-wide summary statistics, we estimated the SNP-based heritability of IgAN at 0.23

5 (95\%CI: 0.15-0.30). Excluding the MHC region reduced SNP-based heritability estimate to $0.12(95 \% \mathrm{CI}$ :

$60.10-0.13)$, suggesting that HLA and non-HLA loci respectively contribute approximately $50 \%$ of the

7 polygenic risk. Using the genetic risk score (expressed as the sum of the risk alleles weighted by their

8 individual effect sizes) based on 30 independently genome-wide significant SNPs (30-SNP GRS)

9 explained $11 \%$ of overall disease variance, a significant improvement compared to the $6 \%$ explained by

10 the previous $15-\mathrm{SNP}_{\mathrm{GRS}}{ }^{4}$.

\section{Classical HLA alleles}

14 To better understand the signal at the HLA locus, we imputed amino-acid sequences and classical HLA alleles at four-digit resolution at class II ( $H L A-D Q B 1,-D Q A 1$ and $-D R B 1)$ and class I ( $H L A-A$, $-B$, and $-C)$ genes (see Methods). We used ethnicity-specific reference panels for imputation, followed by association testing within each ancestral group separately. The analysis of imputed amino-acid sequences in class II genes pointed to $D R B 1$ as the gene with most strongly associated polymorphic positions in both ancestral groups (Extended Data Figure 5). In East Asian cohorts, stepwise conditioning of multiallelic sites demonstrated independently significant associations at DR $\beta 1$ positions 11 and 71, and the same positions were also strongly associated with the disease in Europeans. Specifically, Proline at position 11 (in LD with Arginine at position 71 and corresponding to DRB1*1501) conveyed significant protection in both ancestral groups (Supplementary Table 7). There was also an independently significant risk effect of Arginine at position 71 (in LD with Valine at position 11) with consistent direction of effect across both ancestries. In Europeans, we additionally observed significant effects of two substitutions at position 11, 
medRxiv preprint doi: https://doi.org/10.1101/2021.11.19.21265383; this version posted November 20, 2021. The copyright holder for this preprint (which was not certified by peer review) is the author/funder, who has granted medRxiv a license to display the preprint in perpetuity.

It is made available under a CC-BY-NC-ND 4.0 International license .

2 Glycine (protective) and Leucine (risk). These two substitutions are less frequent in East Asian

3 populations.

5 The association patterns of classical HLA alleles were complex, but generally consistent with the analysis

6 of amino acid sequences. In East Asians, we observed a protective effect of the DRB1*1501-DQA1*0102-

$7 D Q B 1 * 0602$ haplotype (DR15 serotype), and an independent risk effect of $D R B 1 * 0405$, with no

8 significant associations after conditioning for both $D R B 1 * 1501$ and $D R B 1 * 0405$ (Supplementary Table

9 8). In Europeans, we confirmed a strong protective association of the $D R B 1 * 1501-D Q A 1 * 0102$ -

$D Q B 1 * 0602$ haplotype. $D R B 1 * 0405$ had low allelic frequency in Europeans, thus this association was not

11 replicated. Instead, we observed three additional independent European haplotypes (rare in East Asians),

12 including two protective haplotypes, $D R B 1 * 0301-D Q A 1 * 0501-D Q B 1 * 0201$ (DR3 serotype) and

$D R B 1 * 0701-D Q A 1 * 0201-D Q B 1 * 0202 / 0203$ (DR7 serotype), and one risk haplotype DRB1*0101-

$D Q A 1 * 0101-D Q B 1 * 0501$ (DR1 serotype, Supplementary Table 9). After conditioning for the four

independently significant $D R B 1$ alleles residing on these haplotypes, we observed additional independent protective associations of $D Q A 1 * 0102$ and $D P A 1 * 0103$ in Europeans. There were no independently significant associations for the class I genes. Collectively, these analyses point to MHC class II region, with $D R B 1, D Q A 1$, and $D P A 1$ as the most likely candidate genes, but the extended LD across the region, combined with population differences in haplotype diversity and limitations related to imputation preclude further dissection of this complex signal.

\section{Pleiotropic associations of individual IgAN loci}

To describe the full spectrum of pleiotropic associations of individual risk variants, we cross-annotated all non-HLA signals against all genome-wide association studies listed in the NHGRI GWAS Catalogue 
medRxiv preprint doi: https://doi.org/10.1101/2021.11.19.21265383; this version posted November 20, 2021. The copyright holder for this preprint (which was not certified by peer review) is the author/funder, who has granted medRxiv a license to display the preprint in perpetuity.

It is made available under a CC-BY-NC-ND 4.0 International license .

autoimmune and inflammatory diseases, suggesting that these conditions may share pathogenic pathways with IgAN. Among the loci with the highest level of pleiotropy were HORMAD2/LIF and ZMIZ1/PPIF. Other loci with autoimmune pleiotropy were CARD9, TNFSF8/15, REL, OVOL1/RELA, IRF4/DUSP22, and IRF8. Additional novel loci, including TNFRSF13B, PF4V1/CXCL1, LY86/RREB1, and ETS1, showed concordant effects on blood levels of distinct immune cell types and immunoglobulins suggesting that these loci may act through stimulation of immune cell proliferation and immunoglobulin production. When we expanded this analysis to all suggestive loci, we found that 14 of the 47 suggestive loci were associated with the same autoimmune or blood immune cell traits as the genome-wide significant loci, prioritizing these 14 loci for future follow-up studies (Figure 1c).

\section{Shared genetic architecture with serum IgA levels and related traits}

To interrogate shared susceptibility between IgAN and other common diseases, we explored genome-wide genetic correlations with selected immune, infectious, and cardio-metabolic traits using bivariate LD score regression (Figure 2, Supplementary Table 12) ${ }^{10}$. We found negative genetic correlations with primary sclerosing cholangitis $\left(\mathrm{r}_{\mathrm{g}}=-0.37, P=4.1 \times 10^{-3}\right)$, inflammatory bowel disease $\left(\mathrm{r}_{\mathrm{g}}=-0.16, P=9.9 \times 10^{-3}\right)$, and Crohn's disease $\left(\mathrm{r}_{\mathrm{g}}=-0.17, P=1.0 \times 10^{-2}\right)$, and positive correlations with pneumonia $\left(\mathrm{r}_{\mathrm{g}}=0.26, P=9.0 \times 10^{-4}\right)$ and urinary tract infection $\left(\mathrm{r}_{\mathrm{g}}=0.25, P=2.1 \times 10^{-3}\right)$. $^{-}$After excluding HLA, we also observed a positive genetic correlation with serum IgA levels $\left(\mathrm{r}_{\mathrm{g}}=0.31, P=2.1 \times 10^{-3}\right)$, allergy $\left(\mathrm{r}_{\mathrm{g}}=0.18, P=5.2 \times 10^{-3}\right)$, and tonsillectomy ( $\left.\mathrm{r}_{\mathrm{g}}=0.17, P=0.036\right)$, a procedure performed for recurrent pharyngeal infections and also sometimes used to treat relapsing $\operatorname{IgAN}{ }^{11}$. We next performed look-ups of all independent IgAN risk alleles against our latest GWAS for serum IgA levels (Supplementary Table 13). Of 25 non-HLA IgAN risk loci, 9 were nominally $(\mathrm{P}<0.05)$ associated with increased serum IgA levels, all with concordant effects. Conversely, of 31 significant loci for $\operatorname{IgA}$ levels 12 were nominally associated with the risk of $\operatorname{IgAN}$, also with concordant effects. The intersection include four highly significant loci in both GWAS: TNFSF13 (GWAS for IgA 
medRxiv preprint doi: https://doi.org/10.1101/2021.11.19.21265383; this version posted November 20, 2021. The copyright holder for this preprint (which was not certified by peer review) is the author/funder, who has granted medRxiv a license to display the preprint in perpetuity. It is made available under a CC-BY-NC-ND 4.0 International license .

levels $\left.P_{\text {IgA-level }}=9.4 \times 10^{-8}\right), \quad$ TNFSF8/15 $\left(P_{\text {IgA-leve }}=3.2 \times 10^{-10}\right)$, OVOL1/RELA $\left(P_{\text {IgA-level }}=2.6 \times 10^{-22}\right)$, and LIF/HORMAD2 $\left(P_{\text {IgA-level }}=6.7 \times 10^{-17}\right)$. At the same time, the allelic effects at the HLA locus were either opposed or not associated with serum IgA levels, consistent with our genetic correlation analyses in which positive genetic correlation with IgA levels is significant only after exclusion of the HLA region.

\section{Mouse phenotypes support the role of dysregulated IgA production in IgAN}

We tested the candidate gene set defined by our significant GWAS loci for overlap with human ortholog gene sets producing 27 phenotype categories when genetically manipulated in mice. We observed top-most significant enrichments in 'Immune system phenotype' $\left(P=1.3 \times 10^{-12}\right)$ and 'Hematopoietic system phenotype' $\left(P=3.2 \times 10^{-9}\right)$ (Supplementary Table 14). Within these categories, we observed significant enrichments in gene sets whose disruption in mice were associated with 'Abnormal IgA levels' $\left(P=6.4 \times 10^{-}\right.$ $\left.{ }^{6}\right)$ (Extended Data Figure 6), including TNFSF13, TNFSF13B, ITGAM, RELA, REL, CD28, and LYN genes. These observations corroborate our findings of overlapping GWAS loci between serum IgA levels and IgAN and further highlight the role of dysregulated IgA production in the disease pathogenesis. Moreover, this analysis strongly supports the named genes as causal at the corresponding loci and nominates appropriate animal models for experimental follow-up.

\section{Global pathway and tissue/cell type enrichment analyses}

We next used several unbiased strategies to explore biological pathway and tissue enrichments using genome-wide approaches. Pathway-enrichment analysis using MAGMA ${ }^{12}$ revealed 24 enriched gene sets (Extended Data Figure 7). The most strongly enriched GO terms after excluding HLA region were 'Immune System Processes' (enrichment $P=1.4 \times 10^{-9}$ ) and 'Immune Response' (enrichment $P=2.6 \times 10^{-9}$ ). Examination of genome-wide significant non-HLA loci revealed significant enrichments in pathways 
medRxiv preprint doi: https://doi.org/10.1101/2021.11.19.21265383; this version posted November 20, 2021. The copyright holder for this preprint (which was not certified by peer review) is the author/funder, who has granted medRxiv a license to display the preprint in perpetuity. It is made available under a CC-BY-NC-ND 4.0 International license.

involved in innate and adaptive immunity, with the most significant enrichment in the 'Cytokine-Cytokine Receptor Interactions' (enrichment $P=4.0 \times 10^{-11}$ ) (Figure 3a), suggesting several cytokine ligand-receptor interactions may drive disease pathogenesis.

To map the most likely causal tissues and cell types, we partitioned SNP-based heritability across the genome by tissue and cell-type-specific functional scores derived using the FUN-LDA method ${ }^{13}$. We found the most significant heritability enrichments in blood, immune, and gastrointestinal mucosa cells (Figure 3b, Supplementary Table 15). The top enriched cell-types were Primary neutrophils from peripheral blood $\left(P=5.9 \times 10^{-10}\right), P M A-I$-stimulated primary $T$ helper cells $\left(P=2.1 \times 10^{-9}\right)$ and Primary $B$ cells from peripheral blood $\left(P=2.0 \times 10^{-8}\right)$. Analogous analysis performed using experimental mouse datasets pointed to Small intestine inflammatory cells under basal conditions and after Salmonella infection as the top tissue (Extended Data Figure 7). Additional independent analytical methods (DEPICT ${ }^{14}$ and GARFIELD ${ }^{15}$ ) similarly prioritized extra-renal tissues as likely causal in IgAN, converging on hematopoietic, immune, and gastrointestinal tissues as the most likely tissues to harbor causal cell types (Figures 3c and 3d, Supplementary Tables 16-17).

\section{Transcription factor enrichment analysis}

We tested for potential intersection of GWAS signals with a comprehensive database of transcription factor (TF) ChIP-seq datasets using the Regulatory Element Locus Intersection (RELI) algorithm ${ }^{16}$. In the analysis of genome-wide significant and suggestive loci, we detected significant intersection with binding sites for up 32 TFs in 52 immune cell types, with the most significant enrichments for RELA (corrected $\mathrm{P}=5.3 \times 10^{-13}$ ) and NFKB1 (corrected $\mathrm{P}=1.9 \times 10^{-12}$, Figure 4d, Supplementary Table 18). Nearly half of these transcription factors interact with Epstein-Barr-virus super-enhancers, which control B cell proliferation and have previously been found to intersect multiple autoimmune disease loci ${ }^{16,17}$. Moreover, some of the prioritized TFs, such RUNX ${ }^{18}$ and $\mathrm{SMAD}^{19}$ family, are well known to regulate IgA levels, and 
medRxiv preprint doi: https://doi.org/10.1101/2021.11.19.21265383; this version posted November 20, 2021. The copyright holder for this preprint (which was not certified by peer review) is the author/funder, who has granted medRxiv a license to display the preprint in perpetuity. It is made available under a CC-BY-NC-ND 4.0 International license .

2 RUNX3, RUNX2, and RELA loci are significantly associated with IgA levels (see accompanying

3 manuscript), further suggesting perturbations in IgA homeostasis as a primary pathogenetic factor IgAN.

4

\section{Protein-protein interactions and ligand-receptor pairs}

We next tested whether candidate genes within our significant loci encode proteins that are likely to have physical interactions. Using a refined database of high-confidence PPIs, we constructed a network with 76 candidate proteins defined by GWAS using InWeb_IM ${ }^{20}$ and GeneMANIA ${ }^{21}$. The final network composed of a total of 53 nodes and 63 edges exhibited an excess of direct physical interactions compared to null expectation $\left(P<1.0 \times 10^{-16}\right.$, Figure 4c). Gene set enrichment analyses of individual modules in this network (Supplementary Table 19) identified strong enrichments in stress and defense responses (module 1), chemokine signaling pathways (module 4), immune responses (module 5), cytokine-mediated signaling (module 6), and regulation of NF-kB signaling (module 7). Consistent with the observed enrichments in chemokine and cytokine pathways and global cytokine-receptor interactions, we identified enrichment in soluble ligand-receptor pairs, attributable to 16 ligand-receptor pairs spanning 12 independent significant or suggestive loci (enrichment $P=0.01$, Supplementary Table 20). This included APRIL and its receptor TACI encoded by two independent genome-wide significant loci (TNFSF13 and TNFRSF13B, respectively), both implicated in IgA homeostasis. Several IL6-related cytokine-receptor pairs were also identified (IL6-IL6ST, LIF-LIFR/IL6ST, OSM-OSMR/LIFR/IL6ST), with OSM/LIF being encoded by a single genome-wide significant locus, and related receptors being encoded by two independent suggestive loci, OSMR/LIFR and IL6ST. Notably, APRIL is known to alter the glycosylation of IgA ${ }^{22}$, IL6, LIF and OSM are involved in mucosal immunity, and IL6 and LIF leads to enhanced production of galactosedeficient IgA1 $1^{23-25}$. These ligand-receptor pairs nominate candidate genes within corresponding loci, and delineate potentially targetable pathogenetic pathways in IgAN. 
medRxiv preprint doi: https://doi.org/10.1101/2021.11.19.21265383; this version posted November 20, 2021. The copyright holder for this

preprint (which was not certified by peer review) is the author/funder, who has granted medRxiv a license to display the preprint in perpetuity.

It is made available under a CC-BY-NC-ND 4.0 International license .

\section{Functional annotations of individual GWAS loci}

We intersected our association loci with tissue and cell-type specific functional scores and assessed their co-localization with expression quantitative trait loci (eQTL) in primary immune cells, whole blood, and other tissues (see Methods) ${ }^{26}$. We also performed cross-annotation with blood proteome and metabolome data. The majority of top signals mapped to non-coding regions, with the exception of two risk loci (rs4077515 CARD9 p.(Ser12Ile), and rs3803800 TNFSF13 p.(Asn96Ser)). The CARD9 risk allele (rs4077515-T), a nonsynonymous $\mathrm{S} 12 \mathrm{~N}$ substitution in exon 2 of CARD9, is associated with increased blood transcript level of CARD9 and a significant splice QTL in GTEx (Extended Data Figure 8). The protective allele is associated with a truncation of the functional CARD domain, while the risk allele is associated with higher levels of the intact, active isoform, affecting both expression and splicing of CARD9.

For top signals mapping to non-coding regions, we found 79 significant $c i s-\mathrm{eQTL}$ effects with 17 IgAN colocalizations at 20 independent non-HLA risk loci (Supplementary Tables 21-22 and Figure 4a). Twelve loci had 27 significant cis-eQTL effects across 13 primary immune cell types, and 17 of the 27 cis-eQTLs co-localized with IgAN with PP4>0.5 (Supplementary Table 21). In GTEx, we further found 19 cis-eQTL effects for eight IgAN loci across the 28 available tissues and cell types. As an example, two loci (ITGAM/ITGAX and IRF4/DUSP22) mapped specifically to monocytes, an understudied cell type in IgAN. The top signals at these loci intersect monocyte-specific functional elements by FUN-LDA, and co-localize with monocyte-specific eQTLs, with the risk alleles associated with up- and down regulation of ITGAX and IRF4/DUSP22, respectively. As another example of cell type specificity, the ZMIZ1/PPIF locus colocalized with eQTL in NK cells, with the risk allele associated with lower expression of ZMIZ1, which encodes an inhibitor of JAK/STAT signaling and is also involved in TGF- $\beta$ signaling and intestinal inflammation ${ }^{27,28}$. In whole blood, notable eQTL co-localizations included the FCRL3 risk locus, where the risk allele was associated with reduced transcript levels of FCRL3 and FCRL5, and with lower levels of 
medRxiv preprint doi: https://doi.org/10.1101/2021.11.19.21265383; this version posted November 20, 2021. The copyright holder for this preprint (which was not certified by peer review) is the author/funder, who has granted medRxiv a license to display the preprint in perpetuity. It is made available under a CC-BY-NC-ND 4.0 International license.

2 circulating FCRL3 protein (Supplementary Table 23). As FCRL3 is a specific receptor for secretory $3 \quad \operatorname{Ig} \mathrm{A}^{29,30}$, we prioritized FCRL3 is the most likely causal gene at this locus.

5 Three independent IgAN risk loci with colocalizing cis-eQTLs also exhibited trans-eQTL effects, 6 suggesting that these loci induce a more global transcriptional perturbation in blood cells (Supplementary

7 Table 24), For example, the CARD9 locus was associated with 12 trans-eQTL effects, nine of which involve genes in the 'Type I interferon signaling pathway' (enrichment $P=9.5 \times 10^{-18}$ ). The TNFSF8/15 locus was associated with eight trans-eQTL effects with three representing 'Cytokines involved in lymphocyte differentiation' (enrichment $P=4.3 \times 10^{-3}$ ). Interestingly, ITGAX locus had only one trans-eQTL association, lowering mRNA level of IGHG4, encoded by an independent IgAN risk locus on chr.14.

Finally, other loci were associated with perturbations in blood proteome or metabolome. The PF4V1 locus colocalized with PF4V1 cis-eQTL and exhibited multiple pQTL associations with blood protein levels (Supplementary Table 23), including 4 cis and 40 trans-pQTLs proteins. These proteins were most enriched in the GO process of 'Positive Regulation of Neutrophil Chemotaxis' (enrichment $\mathrm{P}=1.3 \times 10^{-3}$ ), providing further evidence as $P F 4 V 1$ as the most likely causal gene for IgAN ${ }^{31}$. Similarly, the $C F H$ locus, where a protective allele is known to tag a common deletion of the CFHR1 and CFHR3 genes $^{2}$, was associated with reduced expression of $C F H R 1$ and $C F H R 3$ in the liver and other tissues including the kidney

(Supplementary Tables 25-26). This allele was also associated with reduced levels of circulating FHR1 (encoded by CFHRI) and higher levels of Factor H in blood (Supplementary Table 23). Moreover, this locus exhibited a widespread proteomic and metabolomic signature in blood, with 64 additional trans-pQTL associations including seven proteins involved in the 'Regulation of complement cascade' (enrichment $P=2.1 \times 10^{-10}$, Figure $4 \mathbf{b}$ ), and altered blood levels of multiple inflammation-related metabolites 
medRxiv preprint doi: https://doi.org/10.1101/2021.11.19.21265383; this version posted November 20, 2021. The copyright holder for this

preprint (which was not certified by peer review) is the author/funder, who has granted medRxiv a license to display the preprint in perpetuity.

It is made available under a CC-BY-NC-ND 4.0 International license .

\section{Integrative prioritization of biological candidate genes}

To systematically prioritize the 311 candidate genes encoded within the 25 significant non-MHC risk loci, we scored for convergence of in silico annotation methods by assigning one point for each of the following criteria: 1) genes most proximal to the top SNP at the locus; 2) genes with a non-synonymous coding variant tagged ( $\mathrm{r} 2 \geq 0.8)$ by the top SNP; 3$)$ genes with a 3D chromatin interaction predicted by the Activityby-Contact $(\mathrm{ABC})$ model $^{34}$ or 4$) \mathrm{GeneHancer}^{35}$, with enhancers that are intersected by variants tagged ( $\mathrm{r} 2 \geq 0.8$ ) by the top SNP or contained within a $95 \%$ credible set for the locus; 5 ) e-genes controlled by at least one eQTL (any GTEx tissue) tagged by the top SNP; 6) e-genes co-localizing with the risk locus in peripheral blood or 7) primary immune cells at PP4>0.5; 8) p-genes encoding blood proteins controlled by at least one cis-pQTL tagged by the top SNP; 9) genes prioritized by PPI network connectivity analysis at $P<0.05 ; 10)$ genes with shared mouse knockout phenotypes; 11) genes within shared MAGMA pathways; 12) genes prioritized by DEPICT, and 13) genes prioritized by manual review of the literature as related to IgAN, IgA production, or mucosal immunity. Using this approach, we prioritized 27 'biological candidate genes', 20 (74\%) of which were also most proximal genes to the top SNP (Figure 5).

\section{Prioritization of plausible drug targets}

To facilitate drug repurposing and to prioritize new targets with GWAS support, we evaluated whether any of the 311 genes contained within significant loci encoded a protein or directly interacted with a protein that was a pharmacologically active drug target either approved or in development for any human disease. In total 13 GWAS loci (52\%) encoded 17 proteins that were already targeted by existing drugs, and 11 loci (44\%) encoded 14 proteins with a direct PPI drug target (Supplementary Table 28 and Figure 6). Among the top 27 high priority 'biological candidates' defined by our scoring system, 11 (40\%) were targeted directly or indirectly by the existing drugs. This included the following drug categories: (1) new inhibitors 
medRxiv preprint doi: https://doi.org/10.1101/2021.11.19.21265383; this version posted November 20, 2021. The copyright holder for this preprint (which was not certified by peer review) is the author/funder, who has granted medRxiv a license to display the preprint in perpetuity.

It is made available under a CC-BY-NC-ND 4.0 International license .

2 of the alternative complement pathway, such as APL-2, AMY-101, and several others ${ }^{36}$ that are currently

3 in clinical trials for $\mathrm{C} 3$ glomerulopathies and age-related macular degeneration; (2) drugs that block the

4 activation of B cells by inhibiting APRIL or TACI interactions such as Atacicept and related drugs that are

5 already in clinal trials for IgAN; (3) drugs that inhibit $\mathrm{T}$ cell activation by targeting ligands of the T-cell

6 stimulatory CD28 protein, such as Belatacept (approved for kidney allograft rejection) or Abatacept

7 (approved for rheumatoid arthritis); (4) drugs that inhibit IL8 (ABX-IL8) or IL8 receptor (Clotrimazole);

8 and (5) drugs that inhibit NF- $\mathrm{kB}$ pathway, such as Bardoxolone that is already in clinical trials for

9 glomerular disorders. We also note that some of our top prioritized causal genes with expression increased

10 by the risk alleles, such as CARD9, ITGAX, PF4V1, CFHR1, or FCAR do not yet have effective drug

11 inhibitors. Other loci encode secreted proteins that appear protective, such as FCRL3 and TNFSF4,

12 suggesting that targeting their upregulation may present a rational therapeutic strategy. Our data

13 additionally implies that activation of transcriptional programs controlled by ZMIZ1 and IRF4, but reduced

14 activation of NF-kB, may also convey a protective effect.

\section{Genome-wide polygenic risk and clinical correlations}

Based on GWAS summary statistics after excluding Immunochip cohorts, we designed and optimized a genome-wide polygenic risk score (GPS) for IgAN. The best-performing GPS was based on LDPred method and assumed 1\% causal variants genome-wide. When tested in the independent GCKD Study ${ }^{37,38}$, the GPS explained approximately $7.3 \%$ of disease risk $\left(P=3.1 \times 10^{-12}\right.$, C-statistic $\left.0.65,95 \% \mathrm{CI}: 0.61-0.68\right)$. We hypothesized that higher polygenic risk captured by the GPS was associated with disease severity and faster progression among cases diagnosed with IgAN. To test this hypothesis, we performed a comprehensive analysis of clinical disease features in association with the GPS (Supplementary Table 29). Consistent with previous observations for the $15-\mathrm{SNP}$ GRS 4 , the GPS was inversely associated with the age at diagnosis, with individuals in the top $20 \%$ tail of the GPS distribution diagnosed 2.2 years sooner 
medRxiv preprint doi: https://doi.org/10.1101/2021.11.19.21265383; this version posted November 20, 2021. The copyright holder for this preprint (which was not certified by peer review) is the author/funder, who has granted medRxiv a license to display the preprint in perpetuity. It is made available under a CC-BY-NC-ND 4.0 International license .

2 (95\% CI: $\left.1.3-3.1, P=2.5 \times 10^{-6}\right)$ compared to the rest of the cohort. The GPS was also significantly associated 3 with faster progression to kidney failure among 2,879 $\mathrm{IgAN}$ cases with long-term follow-up data $(\mathrm{HR}=1.17$ 4 per standard deviation, 95\% CI 1.09-1.24, $P=3.3 \times 10^{-6}$ ). For example, individuals in the top $20 \%$ tail of the 5 GPS distribution had $34 \%$ increased risk of kidney failure $\left(\mathrm{HR}=1.34,95 \% \mathrm{CI}=1.15-1.56, P=2.0 \times 10^{-4}\right)$, while 6 individuals in the top $10 \%$ tail had $48 \%$ increased risk of kidney failure (HR=1.48, 95\%CI $1.22-1.79$, $\left.7 P=6.6 \times 10^{-5}\right)$ compared to the rest of the cohort (Figure 7a).

9 To explore additional clinical associations of the GPS, we performed meta-phenome-wide association study (meta-PheWAS) including a total of 590,515 participants with GWAS data liked to electronic health records, combining UK Biobank and Electronic Health Records and Genomics-III (eMERGE-III) consortium datasets (Figure 7b). We detected a significant positive correlation of the GPS with hematuria, the most common manifestation of $\operatorname{IgAN}\left(\mathrm{OR}\right.$ per standard deviation=1.06, $\mathrm{P}=7.3 \times 10^{-21}$ ). Other notable associations included a protective association with celiac disease $\left(\mathrm{OR}_{\mathrm{SD}}=0.60, \mathrm{P}=4.2 \times 10^{-148}\right)$ and several risk associations, including with rheumatoid arthritis $\left(\mathrm{OR}_{\mathrm{SD}}=1.15, \mathrm{P}=1.1 \times 10^{-39}\right)$, hypothyroidism $\left(\mathrm{OR}_{\mathrm{SD}}=1.05, \mathrm{P}=2.0 \times 10^{-15}\right)$, epistaxis or throat hemorrhage $\left(\mathrm{OR}_{\mathrm{SD}}=1.09, \mathrm{P}=2.6 \times 10^{-9}\right)$, and asthma $\left(\mathrm{OR}_{\mathrm{SD}}=1.02, \mathrm{P}=1.5 \times 10^{-6}\right)$. The above associations remained significant after removing the HLA region from the GPS (Figure 7c, Supplemental Table 30). Notably, the directions of effect were generally consistent with our genome-wide genetic correlation analyses of IgAN with related traits, providing an independent validation of the shared polygenic architecture for these traits.

\section{DISCUSSION:}

Our GWAS of 10,146 cases and 28,751 controls provided support for a highly polygenic architecture of 
medRxiv preprint doi: https://doi.org/10.1101/2021.11.19.21265383; this version posted November 20, 2021. The copyright holder for this preprint (which was not certified by peer review) is the author/funder, who has granted medRxiv a license to display the preprint in perpetuity.

It is made available under a CC-BY-NC-ND 4.0 International license.

2 IgAN, bringing the total number of known risk loci to over 30 and explaining $\sim 11 \%$ of the variance in

3 disease risk. The higher polygenic risk was associated with earlier disease onset and greater lifetime risk

4 of kidney failure, suggesting that polygenic background is predictive of a more aggressive disease. Future

5 studies are needed to test if our polygenic stratification is useful in the diagnosis, clinical risk assessment,

6 or prediction of treatment responsiveness.

8 Our results reinforce the hypothesis that the genetic regulation of IgA production represents the key

9 pathogenic pathway in IgAN. Significant risk loci were enriched in human orthologs of mouse genes that, 10 when genetically modified, cause abnormal IgA levels. We also observed positive genetic correlation

11 between IgAN and serum IgA levels. Moreover, 21 of 25 independent genome-wide significant non-HLA

12 risk loci for IgAN appear to have concordant effect on serum IgA levels, and four of these 21 are also 13 genome-wide significant in a GWAS for serum IgA levels, including loci encoding TNFSF8, APRIL, 14 LIF, and RELA.

16 We observed positive genetic correlations with IgA levels, infections, and tonsillectomy indicating a 17 genetic link between IgA system, common infections, and IgAN. The association with tonsillectomy is 18 especially intriguing, because IgAN is often triggered by pharyngitis, and tonsillectomy has been 19 employed as a treatment for IgAN ${ }^{11}$. In contrast, the observed negative genetic correlations with 20 inflammatory bowel disease may be due to genetically increased production of secretory IgA that has 21 known homeostatic anti-inflammatory and immunosuppressive effects at the level of the gut mucosa ${ }^{39}$. 22 Moreover, our analyses of partitioned heritability clearly support extra-renal tissues as the most likely 23 culprit, prioritizing cells of the immune and hematopoietic systems, and intestinal mucosal tissue, and this 24 extra-renal mapping of causal tissues is fully consistent with the well-established clinical observation that 25 IgAN commonly recurs in kidney allografts after transplantation ${ }^{40}$. In addition, our cell-type specific 
medRxiv preprint doi: https://doi.org/10.1101/2021.11.19.21265383; this version posted November 20, 2021. The copyright holder for this preprint (which was not certified by peer review) is the author/funder, who has granted medRxiv a license to display the preprint in perpetuity.

It is made available under a CC-BY-NC-ND 4.0 International license .

2 analyses point to the role of neutrophils, monocytes, and NK cells in IgAN. These cell types have not

3 been generally considered as relevant to the IgAN pathogenesis based on prior evidence.

5 Our GWAS loci encoded proteins that were more likely to interact physically despite being encoded by

6 distant genomic regions. This included several ligand-receptor pairs that are amenable to therapeutic

7 targeting. IgAN currently lacks effective targeted therapies, and recent pharmaceutical database analyses

8 indicate that drug targets with genetic support are more likely to advance in the development pipeline ${ }^{41}$.

9 Based on our results, we prioritized several candidate genes whose products are targeted by drugs that are

10 presently approved or in clinical development for another condition, and which could be repurposed for

11 IgAN. Mechanistic studies are still needed to confirm our candidate target genes prioritized by our in

12 silico annotations.

13

14 Our study has several limitations. In the meta-analysis, we pooled data across multiple heterogenous cohorts recruited across diverse clinical settings, ancestries, and nationalities. Nevertheless, we used stringent biopsy-based diagnostic criteria, standardized covariate definitions, genetic matching by platform and ancestry, and uniform statistical analysis for each cohort. It is worth pointing out that our dataset is dominated by European (66\%) and East Asian (34\%) ancestry cases, therefore our results may not be generalizable to other patient populations. Notably, IgAN is less frequent among individuals of African ancestry, including African Americans, suggesting that protective genetic effects may exist, but further studies are needed to address this hypothesis. We were also not able to evaluate the contribution of rare variants in this study, and sequencing studies are still needed to evaluate relative contributions of rare and common variants to the overall disease risk. 
ONLINE METHODS

\section{Study Cohorts, Genotyping, Genotype Quality Control and Imputation}

5 The recruitment of patients, genotyping, imputation, and detailed quality control analyses are described by cohort in the Supplemental Notes.

\section{Association Analyses and Meta-analyses}

We conducted genome-wide association analysis in each of the 17 cohorts using imputed genotype dosage data under a logistic regression additive model with adjustment for cohort-specific significant PCs in PLINK v1.942. Subsequently, a fixed effects inverse-variance-weighted meta-analysis was performed to combine results from all cohorts using METAL version 2011-03-25 $5^{43}$ Genome-wide distributions of pvalues were examined visually using quantile-quantile (QQ) plots for each individual cohort as well as for the combined analysis. We also estimated the genomic inflation factors for each cohort. The final metaanalysis QQ plot showed no departure from the expected distribution of p-values, and the genomic inflation factor $(\lambda)$ was estimated at 1.04 (Extended Data Figure S1). In addition, logistic regression association analysis assuming a dominant or a recessive genetic model was performed in PLINK using expected genotype counts, with no evidence of genomic inflation $(\lambda=1.03$ for dominant and 0.94 for recessive model $)$

(Extended Data Figure S3). IgAN is more common in males; thus, we also performed sex-specific analyses, including chromosome X. Genome-wide logistic regression analyses were conducted separately in males and females within each cohort and subsequently meta-analyzed using METAL. A total of 21,236 males and 17,661 females were used in the meta-analysis with overall genomic inflation factors of 1.01 for males and 0.99 for females. A total of $1,990,322$ high quality imputed chromosome $\mathrm{X}$ markers $\left(\mathrm{r}^{2}>0.8\right.$ and MAF $>0.01)$ were analyzed separately by sex, encoding genotypes as $(0,2)$ in males and $(0,1,2)$ in females. 
medRxiv preprint doi: https://doi.org/10.1101/2021.11.19.21265383; this version posted November 20, 2021. The copyright holder for this preprint (which was not certified by peer review) is the author/funder, who has granted medRxiv a license to display the preprint in perpetuity.

It is made available under a CC-BY-NC-ND 4.0 International license.

2 wide significant if at least one SNP in the locus had p-value $\leq 5.0 \mathrm{E}-08$ and it was successfully typed or

3 imputed in $\geq 50 \%$ of analyzed cohorts. Signals with a p-value $\leq 1.0 \mathrm{E}-05$ were considered as suggestive.

4 Summary of meta-analysis results are provided in Table 1 and Supplementary Tables S2-4.

5

6

7

\section{Conditional Analyses}

To detect multiple independent associations at individual genomic loci, we conducted a stepwise conditional analysis using a multi-SNP-based conditional and joint association analysis (COJO $)^{44}$. This method approximates the variance-covariance matrix between association statistics with the LD information from an external reference panel and independent SNPs are selected in a stepwise manner using the GCTA tool version 1.92.0 beta ${ }^{44,45}$. Using our overall meta-analysis summary statistics, we conducted the GCTA conditional analysis with a threshold of $P \leq 5.0 \mathrm{E}-08$ and the LD reference composed of all European and East Asian cohorts from the 1000 Genomes Project Phase 3. Subsequent conditional analyses were performed for makers with a conditioned $P \leq 5.0 \mathrm{E}-08$ until no residual genome-wide significant associations were observed (Supplementary Table S5).

\section{HLA Imputation and Statistical Analysis}

We used the SNP2HLA software to impute classical HLA alleles ${ }^{46}$. The Type 1 Diabetes Genetics Consortium (T1DGC) reference panel of 5,225 Europeans and 8,961 markers was used as a reference set for our European-ancestry cohorts ${ }^{46}$, and the Pan-Asian reference panel of 530 individuals and 8,245 markers was used for our East-Asian cohorts ${ }^{47}$. Only common and high-quality markers (MAF $>0.01$, $\mathrm{R}^{2}>0.8$ ) were used for association analysis. We analyzed each variant using a logistic regression model, assuming additive dosage effects and controlling for significant PCs of ancestry. For testing multi-allelic loci, we used the following logistic regression model: 


$$
\log \text { (odds) }=\beta 0+\sum_{\mathrm{j}=1}^{\mathrm{m}-1} \beta_{\mathrm{j}} \mathrm{X}_{\mathrm{j}, \mathrm{i}}+\sum_{\mathrm{k}=1}^{\mathrm{n}} \beta_{\mathrm{k}} \mathrm{P}_{\mathrm{k}, \mathrm{i}}
$$

where $m$ indicates a total number of alleles at a specific multi-allelic locus, $j$ indicates a specific allele

4 being tested, and $X_{j, i}$ is the imputed dosage for allele $j$ for individual $i ; \beta_{0}$ represents the intercept and $\beta_{j}$ represents the additive effect of an allele $j ; P_{k, i}$ denotes the value for $\mathrm{k}^{\text {th }} \mathrm{PC}$ of individual $i, \mathrm{n}$ is the total number of significant PCs in the dataset; $\beta_{k}$ is the effect size of principal component $k$. We compared log-

7 likelihoods of two nested models: the full model containing the test locus (fitted model) and relevant covariates with the reduced model (null model) without the test locus, but with the same set of covariates. degrees of freedom, from which we calculated p-values:

$$
D=-2 \ln \frac{L_{0}}{L_{1}}, D \sim \chi^{2}(m-1)
$$

where $D$ is the log-likelihood test value (deviance), $L_{0}$ is likelihood of the null model and $L_{l}$ the likelihood of the fitted model. To identify statistically independent effects, we first tested all bi-allelic and multiallelic variants under the logistic regression model, as described above, and ranked them based on the pvalue of the log likelihood test. Next, in a forward stepwise approach, we included in the logistic regression model the most statistically significant variant as a covariate, analyzed all remaining variants and ranked them based on the new p-value of the respective log likelihood test. We repeated the same steps until no variant or no HLA gene had $\mathrm{P} \leq 5.0 \mathrm{E}-08$.

\section{HLA Peptide Sequence Analysis}

21 HLA amino-acid polymorphisms have multiple possible residues at each peptide position. To test the effects of individual amino acid substitution sites we applied a conditional haplotype analysis using fully phased haplotypes across the HLA region. We tested each single amino acid position by first identifying 
medRxiv preprint doi: https://doi.org/10.1101/2021.11.19.21265383; this version posted November 20, 2021. The copyright holder for this preprint (which was not certified by peer review) is the author/funder, who has granted medRxiv a license to display the preprint in perpetuity.

It is made available under a CC-BY-NC-ND 4.0 International license .

2 the $m$ possible amino-acid residues occurring at that position and then using $m-1$ degrees of freedom test

3 to derive $\mathrm{p}$-values with a single amino-acid residue arbitrary selected as a reference. For conditioning on

4 individual amino-acid sites, we used the following procedure: by adding a new amino-acid position to the

5 model, a total of $k$ additional unique haplotypes were generated and tested over the null model (without a

6 new amino-acid position) using the likelihood ratio test with $k$ degrees of freedom. If the new position

7 was independently significant, we further updated the null model to include all unique haplotypes created

8 by all amino-acid residues at both positions to identify another independent position. The procedure was

9 repeated until no statistically significant (conditioned $\mathrm{P} \leq 5.0 \mathrm{E}-08$ ) position was observed.

\section{Heritability and Genetic Correlations}

12 SNP-based heritability was estimated using LD score regression (LDSC software) ${ }^{10}$ based on final metaanalysis summary statistics and LD scores estimated from 1000 Genomes phase 3 European and East

14 Asian populations combined ${ }^{48}$. To assess the contribution of HLA region, we also estimated SNP

15 heritability after excluding the entire MHC region (Chr.6: 28,000,000-33,000,000 bp). To investigate

16 evidence for possible shared genetic effects between IgAN and other traits, we estimated genetic

17 correlations using bivariate LD score regression ${ }^{10}$. For each phenotype, we used GWAS summary

18 statistics from the largest GWAS available with a minimum coverage of 2 million SNPs. We excluded

19 traits with estimated SNP-based heritability $<1 \%$. Genetic correlations were calculated with and without

20 the HLA region. GWAS summary statistics for the relevant immune and cardio-metabolic traits were

21 provided by corresponding consortia, or downloaded from the LD-hub or GWAS catalog; summary

22 statistics for infection-related phenotypes were provided by 23 andMe ${ }^{49}$.

\section{Pleiotropy Maps}


medRxiv preprint doi: https://doi.org/10.1101/2021.11.19.21265383; this version posted November 20, 2021. The copyright holder for this preprint (which was not certified by peer review) is the author/funder, who has granted medRxiv a license to display the preprint in perpetuity.

It is made available under a CC-BY-NC-ND 4.0 International license.

2 All GWAS loci were cross-annotated against the studies listed in the GWAS catalogue (last update: January

3 31, 2019). For each locus, we selected all variants in strong $\operatorname{LD}\left(r^{2} \geq 0.8\right)$ with the top SNP. We then queried

4 the GWAS catalogue for genome-wide significant $(\mathrm{p}<5.0 \mathrm{E}-08)$ associations of the selected SNPs with other

5 diseases and traits. The results were then manually verified by reviewing the original publications to confirm the direction of allelic effects. In cases where there were multiple GWAS for the same trait, we

7 selected the SNP associations based on the largest sample size/lowest P-value and highest LD with our top

8 SNP(s). To evaluate the overlap of pleiotropic effects between significant and suggestive IgAN loci, the

9 traits associated with significant IgAN loci were queried themselves against GWAS catalogue for 10 associations with any of the suggestive SNPs or their proxies. The results were represented as a shared 11 susceptibility network map created in Cytoscape v3.7.0 software.

\section{Polygenic Risk Models}

14 To assess the cumulative effect of independent significant and suggestive loci, we performed a genetic 15 risk score (GRS) analysis. We first created two new GRS models based on the combined meta-analysis results: the 30-SNP model which comprises 30 independent genome-wide significant SNPs (25 non-HLA

17 plus 5 HLA SNPs), and the 77-SNP GRS model which includes the same 30 SNPs plus 47 additional

18 independent SNPs representative of the suggestive loci ( $\mathrm{p}<1.0 \mathrm{E}-05)$. Each GRS was defined as the sum of the number of risk alleles weighted by their effect sizes. We required imputation $\mathrm{R}^{2}>0.3$ for including a SNP in the GRS calculation; individuals typed with Immunochip were excluded. Each GRS was standardized using a Z-score transformation with the mean and standard deviation of the control distribution. We evaluated the performance of each GRS by estimating two goodness of fit measures, Nagelkerke's pseudo $\mathrm{R}^{2}$ and the area under the receiver operating characteristics curve (AUROC).

24 Genome-wide polygenic score (GPS) was calculated using LDpred ${ }^{50}$ and LD-pruning and p-value 25 thresholding $(\mathrm{P}+\mathrm{T})$ methods, similar to the methods in recent studies ${ }^{51,52}$. We used the combined meta- 
medRxiv preprint doi: https://doi.org/10.1101/2021.11.19.21265383; this version posted November 20, 2021. The copyright holder for this preprint (which was not certified by peer review) is the author/funder, who has granted medRxiv a license to display the preprint in perpetuity.

It is made available under a CC-BY-NC-ND 4.0 International license .

analysis including high quality imputed SNPs that overlapped across all cohorts $(2,408,512$ SNPs) but excluding Immunochip cohorts. In the LDPred method, the genetic architecture prior for variant effect sizes is a Gaussian distribution that has two parameters: heritability and a fraction of causal variants. Heritability was estimated using LD score regression, and the fraction of causal variants was used as a tuning parameter $(\rho)$ across the following range: $1,0.3,0.1,0.03,0.01,0.003,0.001,3.0 \mathrm{E}-04,1.0 \mathrm{E}-04$, 1.0E-05, 1.0E-06. Using LDPred, a genome-wide predictor was calculated for each value of $\rho$ and the best performing score was selected. The $\mathrm{P}+\mathrm{T}$ method prunes variants in $\mathrm{LD}$ and considers only variants with a $\mathrm{p}$-value under a certain threshold. Using a range of different $\mathrm{r}^{2}(0.2,0.4,0.6,0.8)$ and $\mathrm{p}$-value thresholds $(1,0.3,0.1,0.03,0.01,0.003,0.001,3.0 \mathrm{E}-04,1.0 \mathrm{E}-04,3.0 \mathrm{E}-05,1.0 \mathrm{E}-05,1.0 \mathrm{E}-06,1.0 \mathrm{E}-07,5.0 \mathrm{E}-08$, 1.0E-08), we again selected the best performing model. The performance of 30-SNP GRS, 77-SNP GRS, and best GPS were compared to the previously published 15-SNP GRS ${ }^{4}$. We additionally tested these models in the German Chronic Kidney Disease (GCKD) study ${ }^{37,38}$, including 314 histologically confirmed IgAN cases versus 663 disease controls with a biopsy-diagnosed kidney disease of anther cause (see Supplemental Note). The analyses were implemented in R v.3.5.2 software.

\section{Gene Set and Pathway Enrichment Analyses}

We defined each IgAN-associated genomic locus by first selecting all proxy SNPs in $\operatorname{LD}\left(\mathrm{r}^{2} \geq 0.5\right)$ with the lead SNP, then extending the genomic region $250 \mathrm{~kb}$ upstream and downstream of the first and last proxy SNP based on genomic position. Each region was then annotated using BiomaRt package, which retrieves Ensembl human gene annotations. Gene sets were created for all genome-wide significant and suggestive loci but excluding the HLA region. For gene set enrichment analysis, we used established gene sets from the Molecular Signatures Database (MSigDB), including GO, KEGG, BioCarta, REACTOME, chemical and genetic perturbations (CGP), and transcription factor targets (TFT). Statistical significance for enrichment was set at FDR q-value $<0.05$. We additionally applied a genome-wide gene set enrichment 
medRxiv preprint doi: https://doi.org/10.1101/2021.11.19.21265383; this version posted November 20, 2021. The copyright holder for this preprint (which was not certified by peer review) is the author/funder, who has granted medRxiv a license to display the preprint in perpetuity.

It is made available under a CC-BY-NC-ND 4.0 International license.

testing approach (excluding the HLA region) using Multi-marker Analysis of GenoMic Annotation (MAGMA) method with default parameters ${ }^{12}$. We also used DEPICT v1 release $194^{14}$ to perform pathway/gene set enrichment and tissue/cell-type analyses. For this analysis, we first used PLINK to identify independently associated SNPs setting $\mathrm{P}<5.0 \mathrm{E}-05$ and $\mathrm{r}^{2}<0.05$ in a physical window of $500 \mathrm{~kb}$. We then used DEPICT to prioritize genes, identified reconstituted gene sets that are enriched in genes from associated regions, and identified tissue and cell-type annotations in which genes from associated regions are highly expressed. Specifically, for each tissue, the DEPICT method performs a $t$-test comparing the tissue-specific expression of IgAN-associated genes versus all other genes. Next, for each tissue, empirical enrichment p-values are computed by repeatedly sampling random sets of loci from the entire genome to estimate the null distribution for the enrichment statistic as previously described ${ }^{53,54}$.

\section{Prioritization of Causal Tissues and Cell Types}

We estimated heritability enrichment of SNPs from GWAS summary statistics for functional categories in tissue and cell-type specific regulatory elements using stratified LD score regression. This method regresses the chi-squared statistics of SNPs from summary statistics on their LD scores ${ }^{10}$, and partitions SNP heritability by functional annotation ${ }^{55}$. We used summary statistics obtained from the meta-analysis of all case-control cohorts excluding the MHC region and excluding the cohorts typed with Immunochip. Heritability enrichment was defined as the proportion of SNP heritability in a specific category, divided by the proportion of SNPs that belong to that category. We first calculated heritability enrichment for a baseline model of 96 non-cell-type-specific functional categories. Along with the 1000 Genomes reference panel, we used this baseline model as a control to assess heritability enrichment in cell-type specific functional annotations. We used functional annotations from the ENCODE and Roadmap Epigenomics Consortium ${ }^{56}$, as well as mouse immune cell-specific functional categories from the Immunological Gene Project (ImmGen) ${ }^{57}$. Using the same method, we evaluated tissue- and cell-specific 
medRxiv preprint doi: https://doi.org/10.1101/2021.11.19.21265383; this version posted November 20, 2021. The copyright holder for this preprint (which was not certified by peer review) is the author/funder, who has granted medRxiv a license to display the preprint in perpetuity.

It is made available under a CC-BY-NC-ND 4.0 International license.

2 heritability enrichments based on the FUN-LDA functional scoring system ${ }^{13}$. As an alternative method,

3 we also used GARFIELD v $2{ }^{15}$ to assess enrichment within the ENCODE and Roadmap-derived

4 regulatory regions.

$6 \quad$ Analysis of Relevant Phenotypes in Mice

7 As a complementary approach to prioritize genes within each locus, we used the Mouse Genome

8 Informatics (MGI) database to identify potential genes the disruption of which causes relevant phenotypes

9 in mice ${ }^{58}$. All phenotypes in MGI are categorized based on the Mammalian Phenotype (MP) ontology and

10 emerge as a result of different genetic models, including targeted knockout animals and chemically

11 induced (ENU) and spontaneous mutations. MGI includes a total of 17,101 mouse genes with Human

12 orthologs $^{59}$. We defined a gene set of 62 genes with mouse orthologs across the 24 non-HLA risk loci for

13 testing against MGI phenotypes to define significantly enriched categories.

\section{Functional Annotations of Individual Loci}

16 For the purpose of detailed functional annotation, we calculated $95 \%$ credible sets for each of the genome 17 wide significant loci using CAVIAR software ${ }^{60}$. We added variants that were neither typed or imputed in 18 our data, but in strong LD with the top SNP based on external reference ( $r 2 \geq 0.8$ in $1000 \mathrm{G}$ European and East Asian populations). These SNP sets were annotated using ANNOVAR to first define any coding variants and their predicted effects. Using FUN-LDA method, we next calculated the posterior probability of a functional effect for each of the selected variants across 127 tissues and cell types as described previously ${ }^{13}$. These SNPs were also interrogated against the following datasets: (1) eQTLs for 13 human immune cell types from the Database of Immune Cell eQTLs (DICE) project $^{61}$; (2) blood eQTLs from the eQTLGen Consortium ${ }^{26}$ (31,684 individuals), (3) GTEx tissue eQTLs ${ }^{62}$ (4) GTEx splicing QTLs (sQTLs); 
medRxiv preprint doi: https://doi.org/10.1101/2021.11.19.21265383; this version posted November 20, 2021. The copyright holder for this preprint (which was not certified by peer review) is the author/funder, who has granted medRxiv a license to display the preprint in perpetuity.

It is made available under a CC-BY-NC-ND 4.0 International license .

$2(\mathrm{~N}=2,820)$ and TwinsUK $(\mathrm{N}=7,824)$ studies $^{64,65}$, and (7) blood pQTLs from three recent well-powered

3 studies $^{66-68}$. We additionally performed co-localization analysis between IgAN and eQTL summary

4 statistics for each GWAS locus using COLOC software ${ }^{69}$. We considered PP4 $>0.5$ as supportive of a shared

5 causal variant.

6

\section{Protein-Protein Interactions}

8 Protein-protein interactions across genome wide significant and suggestive genes have been predicted

9 using InWeb_InBioMap (InWeb_IM) ${ }^{70}$. InWeb_IM is a curated and computationally derived protein-

10 protein network of 420,000 protein-protein interactions that has 2.8 times more interactions than other

11 comparable resources. We used high confidence PPIs from InWeb_IM using the recommended cut off

12 confidence score $\geq 0.1$. All annotated genes within the 76 significant and suggestive IgAN loci were used

13 to probe the PPI database; the final network contained a total of 53 nodes connected by 63 edges.

14 Enrichment P-value was computed using a hypergeometric test and corrected for multiple testing using

15 the method of Benjamini and Hochberg. The network components were grouped into modules based on

16 their pathway categorization; the GLay community clustering algorithm was implemented for module

17 detection and modules were visualized in GeNets ${ }^{71}$. Subsequently, the Clustering with Overlapping

18 Neighborhood Expansion (ClusterONE) algorithm ${ }^{72}$ implemented in Cytoscape ${ }^{73}$ was used to extract

19 protein clusters using the default parameters and the InWeb_IM confidence score as edge weights.

20 Functional and pathway enrichments within the PPI networks were identified using STRING ${ }^{74}$ based on

21 Gene Ontology (GO), KEGG, and Reactome databases. In addition, we used ToppGene Suite ${ }^{75}$ to

22 calculate protein-protein interaction enrichment $\mathrm{p}$-values. A Bonferroni-corrected $\mathrm{P}<0.05$ was used as

23 enrichment significance cut-off. 
medRxiv preprint doi: https://doi.org/10.1101/2021.11.19.21265383; this version posted November 20, 2021. The copyright holder for this preprint (which was not certified by peer review) is the author/funder, who has granted medRxiv a license to display the preprint in perpetuity.

It is made available under a CC-BY-NC-ND 4.0 International license .

2 To identify TF binding sites enriched across IgAN risk loci, we used the RELI (Regulatory Element

3 Locus Intersection) algorithm ${ }^{16}$. RELI uses a set of genetic variants as input, expands the set using LD

4 blocks $\left(\mathrm{r}^{2}>0.8\right)$ and calculates the statistical intersection of the resulting loci with ChiP-seq datasets by

5 counting the number of loci with one or more variants intersecting the TF ChiP-seq peaks. The LD blocks

6 were calculated using 1000 Genomes Project East Asian and European populations combined. The null

7 distribution was generated using 2,000 random repeats of the procedure and was used to calculate z-scores

8 and empirical p-values for the observed intersection. The final reported p-values are Bonferroni-corrected

9 (Pc) for the 1,544 TF datasets tested, as previously published ${ }^{16}$. As input, we used a set of 28 independent

10 genome-wide significant loci ( $\mathrm{P} \leq 5.0 \mathrm{E}-08)$ and a set of 76 loci including genome-wide significant and

11 suggestive variants $(\mathrm{P}<1.0 \mathrm{E}-05)$. A $\mathrm{Pc}<1.0 \mathrm{E}-04$ was used as a significance cut-off for each set.

\section{Ligand-Receptor Pairs}

14 To identify the number of potential ligand-receptor pairs significantly associated with IgAN, we queried

15 The Database of Ligand-Receptor Partners (DLRP) ${ }^{76}$. This database includes cytokines, chemokines, and 16 growth, angiogenesis, and developmental factors, and contains 175 protein ligands, 131 protein receptors

17 and 451 experimentally determined ligand-receptor pairings. To test for ligand-receptor enrichment in our 18 dataset, we used a hypergeometric test for overlap between this dataset and the gene set defined by our 19 significant and suggestive GWAS loci.

\section{Analysis of Drug Targets}

We obtained drug target genes and corresponding drug information from DrugBank ${ }^{77}$, the Therapeutic

Targets Database (TTD) ${ }^{78}$, the Open Targets Platform ${ }^{79}$, and GlobalData combined with manual literature searches. To search for potential drug targets, we extracted all genes in direct PPIs with IgAN risk genes by using the In_Web_IM database. We selected drug target genes that had pharmacological activities and 
medRxiv preprint doi: https://doi.org/10.1101/2021.11.19.21265383; this version posted November 20, 2021. The copyright holder for this preprint (which was not certified by peer review) is the author/funder, who has granted medRxiv a license to display the preprint in perpetuity.

It is made available under a CC-BY-NC-ND 4.0 International license.

2 human orthologues, and that were targeted by any of the drugs that are approved or currently in

3 development (experimental or in clinical trials).

\section{Overall Prioritization of Biological Candidate Genes}

6 Each of the positional candidate genes was scored adopting the following criteria and calculating the

7 number of the satisfied criteria, including: (1) genes most proximal to the top SNP; (2) genes with coding

8 variants in $95 \%$ credible sets and/or high $\mathrm{LD}\left(\mathrm{r}^{2}>0.8\right)$ with the index SNP; (3) genes with promoter

9 chromatin interaction by Activity-by-Contact (ABC) model ${ }^{34}$ or (4) GeneHancer ${ }^{35}$ involving regions

10 intersected by top SNP and its 95\% credible sets/high LD proxies; (5) e-genes controlled by at least one

11 eQTL (any tissue) tagged by the top SNP in any tissues (primary immune cells, whole blood, kidney,

12 GTEx); (6) e-genes co-localized with the risk locus in blood or (7) primary immune cells with PP4 $>0.5$;

13 (8) p-genes controlled by at least one blood pQTL tagged by the top SNP; (9) genes prioritized by PPI

14 network connectivity analysis at $\mathrm{P}<0.05$; (10) genes that when knocked out in mice produce at least two

15 phenotype labels: 'immune system', 'haematopoietic system', or 'cellular phenotype'; (11) genes

16 prioritized by MAGMA, (12) DEPICT with gene-based $\mathrm{p}<0.05$, or (13) manual review of the literature as

17 related to IgAN, IgA production, or mucosal immunity.

\section{Genotype-phenotype Correlations}

Our polygenic risk models (15-SNP, 30-SNP, 77-SNP, and GPS) were tested for clinical correlations in the subset of cases with available clinical data. We fitted each standardized risk score in a regression model to predict clinical disease features at the time of diagnosis, including age at biopsy, estimated glomerular filtration rate (GFR), proteinuria, microhematuria, hypertension (HTN), and gross hematuria.

The GFR was estimated using the CKD-EPI formula in adults ${ }^{80}$ and Schwartz formula in pediatric cases $^{81}$. The estimated GFR was normalized with a natural logarithm transformation; proteinuria was 
medRxiv preprint doi: https://doi.org/10.1101/2021.11.19.21265383; this version posted November 20, 2021. The copyright holder for this preprint (which was not certified by peer review) is the author/funder, who has granted medRxiv a license to display the preprint in perpetuity.

It is made available under a CC-BY-NC-ND 4.0 International license.

normalized with a $\ln (\mathrm{P} 24+1)$ transformation; microhematuria was assessed with urinary dipstick and defined as positive if $1+$ or greater; gross hematuria was defined by the reported history of red urine before a diagnostic biopsy; hypertension was defined as systolic blood pressure $\geq 140 \mathrm{mmHg}$ and/or diastolic blood pressure $\geq 90 \mathrm{mmHg}$, or anti-hypertensive medication use. For the analysis of longitudinal outcomes, we performed survival analysis with the primary outcome of kidney failure defined as eGFR $<15 \mathrm{ml} / \mathrm{min} / 1.73 \mathrm{~m}^{2}$ or initiation of kidney replacement therapy (dialysis or kidney transplantation). All analyses were adjusted for age, gender, site, and race/ethnicity. The analyses were implemented in R v3.5.2.

\section{Phenome-wide association studies (PheWAS)}

We performed meta-analysis of PheWAS results (meta-PheWAS) across two large biobank-based datasets: Electronic Medical Records and Genomics-III (eMERGE-III) and the UK Biobank (UKBB).

The eMERGE-III network provides access to EHR information linked to GWAS data for 102,138 individuals; detailed quality control analyses of genetic data have been described previously ${ }^{82-84}$. Briefly, GWAS datasets were imputed using the latest multiethnic Haplotype Reference Consortium (HRC) panel using Michigan Imputation Server ${ }^{85}$. The imputation was performed in 81 batches across the 12 contributing medical centers participating in eMERGE-I, II, and III. For post-imputation analyses, we included only markers with minor allele frequency (MAF) $\geq 0.01$ and $R^{2} \geq 0.8$ in $\geq 75 \%$ of batches. A total of 7,529,684 variants were retained for the GPS analysis. For principal component analysis (PCA), we used FlashPCA ${ }^{86}$ on a set of 48,509 common $(\mathrm{MAF}>0.01)$ and independent variants (pruned in PLINK with --indep-pairwise 500500.05 command). The UKBB is a large prospective population-based cohort that enrolled individuals ages 40-69 for the purpose of genetic studies ${ }^{87}$. This cohort is comprised of 488,377 individuals recruited since 2006, genotyped with high-density SNP arrays, and linked to electronic health record data. All individuals underwent genome-wide genotyping with UK Biobank 
medRxiv preprint doi: https://doi.org/10.1101/2021.11.19.21265383; this version posted November 20, 2021. The copyright holder for this preprint (which was not certified by peer review) is the author/funder, who has granted medRxiv a license to display the preprint in perpetuity.

It is made available under a CC-BY-NC-ND 4.0 International license .

2 Axiom array from Affymetrix and UK BiLEVE Axiom arrays ( 825,000 markers). Genotype imputation

3 was carried out using a 1000 Genomes reference panel with IMPUTE4 software ${ }^{88-90}$. We then applied QC

4 filters similar to eMERGE-III, retaining 9,233,643 common (MAF $\geq 0.01$ ) variants imputed with high

5 confidence $\left(R^{2} \geq 0.8\right)$. For principal component analysis by FlashPCA ${ }^{86}$, we used a set of 35,226 variants

that were common $(\mathrm{MAF}>0.01)$ and pruned using the following command in PLINK --indep-pairwise

750050 0.05. In order to test the GPS for associations phenome-wide across both eMERGE and UKBB

8 datasets, we first harmonized the coded diagnoses data by converting all available ICD-10-CM codes to

9 ICD-9-CM system. This approach was motivated by the fact that the great majority of data for eMERGE-

10 III participants is already coded using ICD-9 system, and ICD-10 codes are more granular, thus a reverse

11 conversion leads to mapping errors. After the conversion, the 102,138 genotyped eMERGE participants

12 had a total of 20,783 ICD-9 codes that were then mapped to 1,817 distinct phecodes (disease-specific

13 groupings of ICD codes). The 488,377 UKBB participants had a total of 10,221 ICD-9 codes that that

14 were mapped to 1,817 phecodes. Phenome-wide associations were performed using the PheWAS R

15 package ${ }^{91}$. The package uses pre-defined "control" groups for each phecode. The case definition requires

16 a minimum of two ICD-9 codes from the "case" grouping of each phecode. In total, all 1,817 phecodes

17 were tested using logistic regression with each phecode case-control status as an outcome and the

polygenic score IgA nephropathy adjusted for age, sex, study site or batch, and 3 principal components of

ancestry as a predictor. We then performed meta-PheWAS across both datasets combined using metagen

with fixed effect in PheWAS R library ${ }^{91}$. To establish significant disease associations in PheWAS, we set

the Bonferroni-corrected statistical significance threshold at $2.75 \mathrm{E}^{-05}(0.05 / 1,817)$ correcting for 1,817

independent phecodes tested. 
medRxiv preprint doi: https://doi.org/10.1101/2021.11.19.21265383; this version posted November 20, 2021. The copyright holder for this preprint (which was not certified by peer review) is the author/funder, who has granted medRxiv a license to display the preprint in perpetuity.

It is made available under a CC-BY-NC-ND 4.0 International license .

\section{Web Resources}

3

4 COLOC: https://cran.r-project.org/web/packages/coloc/

5 DICE: https://dice-database.org/

6 EAGLE: https://data.broadinstitute.org/alkesgroup/Eagle/

7 eQTLGen: https://www.eqtlgen.org/

8 DEPICT: $h$ ttps://data.broadinstitute.org/mpg/depict/index.html

9 DLRP: https://dip.doe-mbi.ucla.edu/dip/DLRP.cgi

10 DrugBank: https://www.drugbank.ca

11 FUN-LDA: http://www.columbia.edu/ ii2135/funlda.html

12 GARFIELD: $\mathrm{https}$ :/www.ebi.ac.uk/birney-srv/GARFIELD/

13 GCTA-COJO: https://cnsgenomics.com/software/gcta/\#COJO

14 GeNets: $\underline{h t t p: / / a p p s . b r o a d i n s t i t u t e . o r g / g e n e t s}$

15 GlobalData: https://www.globaldata.com/industries-we-cover/pharmaceutical

16 GSEA: http://software.broadinstitute.org/gsea/msigdb/

17 GTEx: https://gtexportal.org/home/

18 GWAS catalog: https://www.ebi.ac.uk/gwas

19 InWeb: http://apps.broadinstitute.org/genets\#InWeb_InBiomap

20 KING: http://people.virginia.edu/ wc9c/KING/

21 Kidney eQTL Atlas: http://susztaklab.com/eqtl

22 LD hub: http://ldsc.broadinstitute.org/ldhub

23 LDpred: https://github.com/bvilhjal/ldpred

24 LDSC: https://github.com/bulik/ldsc

25 Metabolomics GWAS Server: http://metabolomics.helmholtz-muenchen.de/gwas/

26 METAL: http://csg.sph.umich.edu/abecasis/Metal/

27 MGI: http://www.informatics.jax.org

28 MINIMAC3: http://genome.sph.umich.edu/wiki/Minimac3

29 MIP: https://imputationserver.sph.umich.edu

30 NEPTUNE eQTL Browser: $\underline{\text { http://nephqtl.org/ }}$

31 Open Targets: https://www.targetvalidation.org

32 PheWAS: https://github.com/PheWAS/PheWAS

33 PheWeb: http://pheweb.sph.umich.edu/SAIGE-UKB/

34 PLINK: https://www.cog-genomics.org/plink/1.9/

35 RELI: https://github.com/WeirauchLab/RELI

36 SNP2HLA: http://software.broadinstitute.org/mpg/snp2hla/snp2hla_manual.html

37 STRING: https://string-db.org

38 ToppGene: https://toppgene.cchmc.org

39 TTD: https://db.idrblab.org/ttd 
medRxiv preprint doi: https://doi.org/10.1101/2021.11.19.21265383; this version posted November 20, 2021. The copyright holder for this preprint (which was not certified by peer review) is the author/funder, who has granted medRxiv a license to display the preprint in perpetuity.

It is made available under a CC-BY-NC-ND 4.0 International license .

\section{Acknowledgments}

We are grateful to all study participants across multiple nephrology centers worldwide for their contributions to this manuscript. This work was supported by the following institutions, grants, and funding agencies: Columbia University, Columbia Glomerular Center, IGA Nephropathy Foundation of America, and National Institute for Diabetes and Digestive Kidney Diseases (NIDDK) grants R01DK105124 (KK, JN, BAJ) and RC2-DK116690 (KK), R01-DK082753 (AGG, JN, KK, FS, BAJ, RJW). Additional support was provided by R01LM013061 (KK), U01HG008680 (KK), U01AI152960 (KK), R01-DK078244 (JN, BAJ), R01-AI149431 (JN, BAJ), National Science Foundation of China (82022010, ZX; 82070733, ZH); Beijing Natural Science Foundation (Z190023,ZX); DFG Project-ID 192904750 CRC 992 Medical Epigenetics (AK, PS), DFG Project-ID 431984000 - CRC 1453 (AK), and the EQUIP Program for Medical Scientists, Faculty of Medicine, University of Freiburg (PS). JBH, SP, KL, and WM were supported by R01HG010730, U01AI130830, R01NS099068, R01AI024717, R01AR073228, U01AI150748, R01AI148276, P01AI150585 and the US Department of Veterans Affairs Merit Award I01-BX001834 to JBH. DPG was supported by the St Peter's Trust for Kidney, Bladder and Prostate Research. The UK cohort data was generated as a result of a grant from Kidney Research UK and the Medical Research Council (JB and DG). The German STOP-IgAN study was supported by the Deutsche Forschungsgemeinschaft (DFG, German Research Foundation) - CRU 5011 - Project-ID 445703531 (J.F., T.R.). The GCKD (German Chronic Kidney Disease) study was funded by grants from the German Ministry of Education and Research (BMBF, No. 01ER0804) and the KfH Foundation for Preventive Medicine. Unregistered grants to support the study were provided by Bayer, Fresenius Medical Care, and Amgen. Genotyping was supported by Bayer Pharma AG. The recruitment of Polish cases with IgA nephropathy was sponsored by the Polish Kidney Genetics Network (POLYGENES), a collaborative effort between Columbia University and Poznań University of Medical Sciences, Poland. The recruitment of Czech patients with IgA nephropathy was supported by the research project of General University Hospital in Prague (RVO-VFN64165). The recruitment of Russian cohort was supported by the 
medRxiv preprint doi: https://doi.org/10.1101/2021.11.19.21265383; this version posted November 20, 2021. The copyright holder for this preprint (which was not certified by peer review) is the author/funder, who has granted medRxiv a license to display the preprint in perpetuity.

It is made available under a CC-BY-NC-ND 4.0 International license .

2 Government Assignment of the Russian Ministry of Health, Assignment \#200080056 of the Veltischev

3 Research and Clinical Institute for Pediatrics of the Pirogov Russian National Research Medical

4 University. The recruitment of the Swedish cohort was supported by the Nephrology and Rheumatology

5 Departments at Karolinska University Hospital and Karolinska Institutet, Stockholm, and grants from the

6 Swedish Society of. Medicine. We thank the Immunopathology Working Group of the Italian Society of

7 Nephrology (ISN) for inviting their member sites to contribute to this study. We are also grateful to the

8 Pediatric Nephrology Research Consortium (PNRC) for hosting and co-sponsoring the GIGA-kids Study

9 that recruited pediatric patients with IgAN across PNRC sites. We are additionally grateful to Corinna

10 Bowers for coordinating GIGA-kids and PMRC-based recruitment, Dr. Joann Narus for coordinating

11 recruitment at the University of Utah, Dr. Ewa Elenberg and Dr. Shweta Shah for helping enroll subjects

12 from Texas Children's Hospital and Adisak Suwanichkul for sample shipping. The recruitment of the

13 Korean cohort was supported by the Seoul National University Hospital Human Biobank, a member of

14 the National Biobank of Korea, financed by the Ministry of Health and Welfare, Republic of Korea. We

15 are grateful to the International Multiple Sclerosis Genetics Consortium (IMSGC), the Inflammatory

16 Bowel Disease Genetics Consortium (IBDGC), the International Myositis Consortium (IMC), the

17 Feinstein Institute for Medical Research, the French Biological Ressource Center for MS Genetics

18 (REFGENSEP), Genethon, and INSERM for contributing Immunochip controls for the purpose of this

study. We would also like to thank the Population Architecture Using Genomics and Epidemiology

(PAGE) consortium, funded by the National Human Genome Research Institute (NHGRI) with co-

funding from the NIMHD, for providing population controls genotyped with MEGA chip for this study.

The funding sources were not involved in the study design, collection, analysis, and interpretation of data, 
medRxiv preprint doi: https://doi.org/10.1101/2021.11.19.21265383; this version posted November 20, 2021. The copyright holder for this preprint (which was not certified by peer review) is the author/funder, who has granted medRxiv a license to display the preprint in perpetuity.

It is made available under a CC-BY-NC-ND 4.0 International license .

\section{Authors Contributions}

K. Kiryluk and A.G. Gharavi conceived the study, provided overall supervision of the project, and made the decision to publish the findings; E. Sanchez-Rodriguez and N. Mladkova performed quality control, imputation, and GWAS association analyses for GWAS and Immunochip discovery cohorts. E. SanchezRodriguez performed final statistical analyses, meta-analyses, fine-mapping studies, functional annotations, and drug target analyses; F. Zanoni and A. Khan designed polygenic risk scores, tested for genome-wide genetic correlations, and performed clinical correlation analyses; L. Liu performed analysis of the HLA locus; J.B. Harley, M. Weirauch, S. Eswar, S. Parameswaran, and L. Kottyan performed RELI transcription factor analysis; I. Ionita-Laza consulted on the statistics and functional annotation of GWAS loci; K. Kiryluk, A.G. Gharavi, J. Novak provided biological interpretation of GWAS loci; X. Zhou and H. Zhang coordinated recruitment, genotyping, and analysis of the Beijing cohorts; F. Scolari coordinated recruitment activities across the Italian network of clinical recruitment sites; Y. Caliskan coordinated recruitment activities across the Turkish recruitment sites; H. Trimarchi coordinated recruitment across the Argentinian network of clinical recruitment sites; V.Tesar and D.Maixnerova coordinated the recruitment of the Czech cohort; J. Xie and N. Chan coordinated recruitment, genotyping, and analysis of the Shanghai cohorts; H. Suzuki recruited and clinically characterized the Japanese Discovery cohort. H. Lee, J. Park, BL Cho, Y.S. Kim, and D.K. Kim recruited and clinically characterized the Korean Discovery cohort. J. Floege and T. Rauen contributed DNA and clinical data for the German STOP-IgAN cohort; K. Kiryluk, R. Nelson, R. Wyatt, and B. Smoyer led the GIGA-kids study in collaboration with the Pediatric Nephrology Research Consortium (PNRC); M. Marasa, O. Balderes, J.Y. Zhang coordinated recruitment at Columbia University and managed clinical data and DNA samples; J. Barratt, and D. P. Gale provided summary statistics for the UK GWAS cohort; R. P. Lifton contributed previously published European and Beijing GWAS cohorts; A. B. Ekici, K-U. Eckardt, and A. Köttgen contributed German cases to the Immunochip discovery cohorts, and P. Schlosser performed polygenic risk score validation studies in the GCKD cohort; D. van Heel, B. Cotsapas, C. Wijmenga, A. Franke, V. 
medRxiv preprint doi: https://doi.org/10.1101/2021.11.19.21265383; this version posted November 20, 2021. The copyright holder for this preprint (which was not certified by peer review) is the author/funder, who has granted medRxiv a license to display the preprint in perpetuity. It is made available under a CC-BY-NC-ND 4.0 International license .

2 Annese, and P.K. Gregersen contributed Illumina Immunochip idat files for population controls; R. Loss

and E. Kenny contributed Illumina MEGA chip idat files for population controls. All other co-authors contributed to the recruitment and clinical characterization of IgAN patients and controls recruited from their respective clinical centers. All authors have read and approved the final version of manuscript.

\section{Declaration of Interests}

B.A.J. and J.N. are co-founders, co-owners of, and consultants for Reliant Glycosciences, LLC and are co-inventors on US patent application 14/318,082 (assigned to UAB Research Foundation). A.G. has served on an advisory board for Novartis, Travere and Natera and receives research grant funding from the Renal Research Institute and Natera. K.K. has served on an advisory board for Goldfinch Bio and Gilead. The other authors report no conflict of interest.

\section{Ethics Statement}

All subjects provided informed consent to participate in genetic studies, and the Institutional Review Board of Columbia University (protocol number IRB-AAAC7385) as well as local ethics review committees for each of the individual cohorts approved our study protocol.

\section{Data Availability}

Primary genotype data for previously published cohorts is available through dbGAP under accession number phs000431.v2.p1. Genotype data for newly added cohorts will be available through dbGAP upon publication (accession number pending). Our IRB determined that the use of this dataset is restricted to genetic studies of kidney disease. The PAGE consortium control genotype data is available on dbGAP under accession number phs000356.v2.p1. The Electronic Medical Records and Genomics-III (eMERGE- 
medRxiv preprint doi: https://doi.org/10.1101/2021.11.19.21265383; this version posted November 20, 2021. The copyright holder for this preprint (which was not certified by peer review) is the author/funder, who has granted medRxiv a license to display the preprint in perpetuity. It is made available under a CC-BY-NC-ND 4.0 International license.

2 III) imputed genotype and phenotype data are available through dbGAP, accession number:

3 phs001584.v2.p2. The UK Biobank genotype and phenotype data are available through the UK Biobank

4 web portal https://www.ukbiobank.ac.uk/. All data and summary statistics are also available from the 5 corresponding authors upon reasonable request. 
medRxiv preprint doi: https://doi.org/10.1101/2021.11.19.21265383; this version posted November 20, 2021. The copyright holder for this

preprint (which was not certified by peer review) is the author/funder, who has granted medRxiv a license to display the preprint in perpetuity.

It is made available under a CC-BY-NC-ND 4.0 International license .

2 Table 1. New and known genome-wide significant loci based on meta-analysis.

\begin{tabular}{|c|c|c|c|c|c|c|c|c|c|c|c|c|}
\hline Chr & $\begin{array}{l}\text { Location } \\
\qquad\left(\mathrm{bp}^{\mathrm{a}}\right)\end{array}$ & $\mathrm{SNP}^{\mathrm{b}}$ & Locus & $\begin{array}{l}\text { Risk } \\
\text { Allele }\end{array}$ & $\begin{array}{c}\text { Freq. } \\
\text { European } \\
\text { Controls }\end{array}$ & $\begin{array}{c}\text { Freq. } \\
\text { Asian } \\
\text { Controls }\end{array}$ & OR & P-value & $Q$ test & $\mathrm{I}^{2}$ & $\begin{array}{l}\text { Supporting } \\
\text { Cohorts }\end{array}$ & New \\
\hline 1 & $157,542,162$ & rs849815 & $F C R L$ & $A$ & 0.66 & 0.50 & 1.14 & 3.9E-09 & 0.57 & 0 & GWAS + IC & Known \\
\hline 1 & $173,146,357$ & rs4916312 & TNFSF4 & $A$ & 0.35 & 0.07 & 1.14 & $5.0 \mathrm{E}-08$ & 0.68 & 0 & GWAS + IC & New \\
\hline 1 & $196,686,918$ & rs6677604 & $\mathrm{CFH}$ & $\mathrm{G}$ & 0.80 & 0.93 & 1.21 & $1.5 \mathrm{E}-17$ & 0.97 & 0 & GWAS + IC & Known \\
\hline 1 & $196,603,302$ & rs12029571 & $\mathrm{CFH}$ & $A$ & 0.22 & 0.35 & 1.12 & 2.5E-06 & 0.88 & 0 & GWAS & Known \\
\hline 2 & $61,092,678$ & rs842638 & $R E L$ & $\mathrm{~T}$ & 0.44 & 0.15 & 1.17 & 9.6E-10 & 0.002 & 63.8 & GWAS & New \\
\hline 2 & $204,584,759$ & rs3769684 & $C D 28$ & $\mathrm{~T}$ & 0.95 & 0.49 & 1.19 & $5.1 \mathrm{E}-11$ & 0.93 & 0 & GWAS + IC & New \\
\hline 4 & $74,725,320$ & rs6828610 & PF4V1/CXCL8 & $G$ & 0.16 & 0.27 & 1.14 & $3.5 \mathrm{E}-08$ & 0.98 & 0 & GWAS & New \\
\hline 6 & 249,571 & rs12201499 & IRF4/DUSP22 & $\mathrm{C}$ & 0.12 & 0.28 & 1.18 & 3.1E-11 & 0.39 & 5.1 & GWAS & Known \\
\hline 6 & $7,214,676$ & rs12530084 & $L Y 86$ & C & 0.77 & 0.51 & 1.13 & 1.3E-09 & 0.49 & 0 & GWAS & New \\
\hline 6 & $32,389,305$ & rs9268557 & HLA-DRA & $\mathrm{C}$ & 0.51 & 0.57 & 1.24 & $4.5 \mathrm{E}-47$ & 0.00 & 72.4 & GWAS + IC & Known \\
\hline 6 & $32,667,829$ & rs9275355 & $H L A-D Q B / D Q A$ & C & 0.23 & 0.33 & 1.26 & 1.7E-34 & 0.21 & 24.8 & GWAS & Known \\
\hline 6 & $32,599,999$ & rs9272105 & HLA-DQA & $A$ & 0.60 & 0.45 & 1.25 & $1.2 \mathrm{E}-28$ & 0.001 & 73.2 & GWAS + IC & Known \\
\hline 6 & $32,681,631$ & rs9275596 & $H L A-D Q B / D Q A$ & $\mathrm{~T}$ & 0.66 & 0.81 & 1.33 & $3.2 \mathrm{E}-36$ & 0.05 & 45.9 & GWAS + IC & Known \\
\hline 6 & $33,074,288$ & rs3128927 & $H L A-D P A / D P B$ & C & 0.73 & 0.83 & 1.22 & $1.5 \mathrm{E}-25$ & 0.38 & 6.1 & GWAS + IC & Known \\
\hline 6 & $167,445,139$ & rs2282859c & CCR6 & C & 0.01 & 0.15 & 1.20 & $3.9 \mathrm{E}-08$ & 0.06 & 43.8 & GWAS + IC & New \\
\hline 8 & $6,808,722$ & rs2075836 & $D E F A$ & $\mathrm{~T}$ & 0.31 & 0.30 & 1.21 & $5.8 \mathrm{E}-11$ & 0.90 & 0 & GWAS & Known \\
\hline 8 & $56,852,496$ & rs75413466 & $L Y N$ & $A$ & 0.02 & 0.06 & 1.40 & $1.4 \mathrm{E}-10$ & 0.80 & 0 & GWAS + IC & New \\
\hline 8 & $124,765,474$ & rs34354351 & ANXA3 & $\mathrm{T}$ & 0.17 & 0.32 & 1.15 & $3.5 \mathrm{E}-08$ & 0.84 & 0 & GWAS & New \\
\hline 9 & $117,643,362$ & rs13300483 & TNFSF8/15 & $\mathrm{T}$ & 0.24 & 0.31 & 1.13 & 1.3E-08 & 0.88 & 0 & GWAS + IC & New \\
\hline 9 & $139,266,496$ & rs4077515 & CARD9 & $\mathrm{T}$ & 0.41 & 0.29 & 1.14 & $2.6 \mathrm{E}-11$ & 0.41 & 1.8 & GWAS + IC & Known \\
\hline 10 & $65,363,048$ & rs57917667 & REEP3 & $\mathrm{G}$ & 0.02 & 0.19 & 1.22 & 1.1E-08 & 0.91 & 0 & GWAS & New \\
\hline 10 & $81,043,743$ & rs1108618 & ZMIZ1 & A & 0.60 & 0.49 & 1.14 & $1.9 \mathrm{E}-10$ & 0.43 & 0.3 & GWAS + IC & New \\
\hline 11 & $65,555,524$ & rs10896045 & RELA & A & 0.30 & 0.48 & 1.18 & 4.7E-13 & 0.03 & 50.6 & GWAS & New \\
\hline 11 & $128,487,069$ & rs7121743 & ETS1 & C & 0.16 & 0.47 & 1.13 & $3.4 \mathrm{E}-08$ & 0.79 & 0 & GWAS & New \\
\hline 14 & $107,222,014$ & rs751081288 & $I G H$ & $A$ & 0.43 & 0.53 & 1.17 & 1.9E-08 & 0.74 & 0 & GWAS & New \\
\hline 16 & $31,357,760$ & rs11150612 & ITGAM & A & 0.64 & 0.27 & 1.16 & 8.4E-14 & 0.10 & 36.8 & GWAS+IC & Known \\
\hline 16 & $86,017,715$ & rs1879210 & IRF8 & $\mathrm{T}$ & 0.64 & 0.86 & 1.14 & 9.9E-09 & 0.96 & 0 & GWAS+IC & New \\
\hline 17 & $7,462,969$ & rs3803800 & TNFSF13 & $A$ & 0.21 & 0.32 & 1.15 & $1.2 \mathrm{E}-10$ & 0.19 & 27.1 & GWAS+IC & Known \\
\hline 17 & $16,851,450$ & rs57382045 & TNFRSF13B & A & 0.11 & 0.33 & 1.16 & 3.4E-09 & 0.84 & 0 & GWAS & New \\
\hline 19 & $55,397,217$ & rs1865097 & FCAR & $A$ & 0.30 & 0.38 & 1.12 & 7.7E-09 & 0.49 & 0 & GWAS+IC & New \\
\hline 22 & $30,512,478$ & rs4823074 & HORMAD2/LIF & G & 0.54 & 0.67 & 1.16 & $7.8 \mathrm{E}-15$ & 0.51 & 0 & GWAS & Known \\
\hline
\end{tabular}

3

4 Chr., chromosome; freq., frequency; Q test, p-value for Cochrane's Q statistic; $I^{2}$, heterogeneity index; IC, Immunochip

5 a Genome Reference Consortium Human Build 37 (hg19).

6 b Only independent SNPs in each locus are included.

$7 \quad{ }^{c}$ East Asian genome-wide significant specific signal.

8 
medRxiv preprint doi: https://doi.org/10.1101/2021.11.19.21265383; this version posted November 20, 2021. The copyright holder for this preprint (which was not certified by peer review) is the author/funder, who has granted medRxiv a license to display the preprint in perpetuity.

It is made available under a CC-BY-NC-ND 4.0 International license .

Figure 1. Transethnic GWAS for IgAN: (a) Manhattan plot for the combined meta-analysis across 38,897 individuals; the dotted horizontal line indicates a genome-wide significant $p$-value 5.0E-08; $y$-axis shows -log10 of $p$-values and is truncated to accommodate the HLA signal; $x$-axis shows genomic position for each chromosome (1-22 and X); red: novel genome-wide significant loci associated with IgAN; dark blue: previously known loci reaching genome-wide significance in this study; locus name based on the top candidate gene based on our biological prioritization strategy; (b) Effect size (beta, $y$-axis) as a function of minor allelic frequency (MAF, x-axis) for suggestive and significant GWAS loci; minor alleles with positive effect sizes (risk alleles) are represented at the top and negative effect sizes (protective alleles) are represented at the bottom; a 3-degree polynomial regression curve was fitted to illustrate positive and negative correlations; correlation coefficients $(R)$ and their corresponding Pvalues $(P)$ are also provided; light-blue circles represent genome-wide significant loci and are labeled using the most likely candidate gene per locus, blue triangles represent suggestive loci. (c) Pleiotropic effects of non-HLA GWAS loci for IgAN based on the NHGRI GWAS catalogue; only genome-wide significant associations in LD ( $r 2>0.5)$ with IgAN top SNPs are included as edges; yellow are diseases and traits sharing at least one locus with IgAN; edge thickness is proportional to the LD between the IgAN top SNP and the lead association SNP for GWAS catalogue traits; concordant effects are indicated in red, opposed effects in blue; green nodes represent IgAN GWAS loci, light-blue nodes are IgAN suggestive loci; only 13 suggestive loci sharing at least one pleiotropic association with a genome-wide significant IgAN locus are depicted.

a

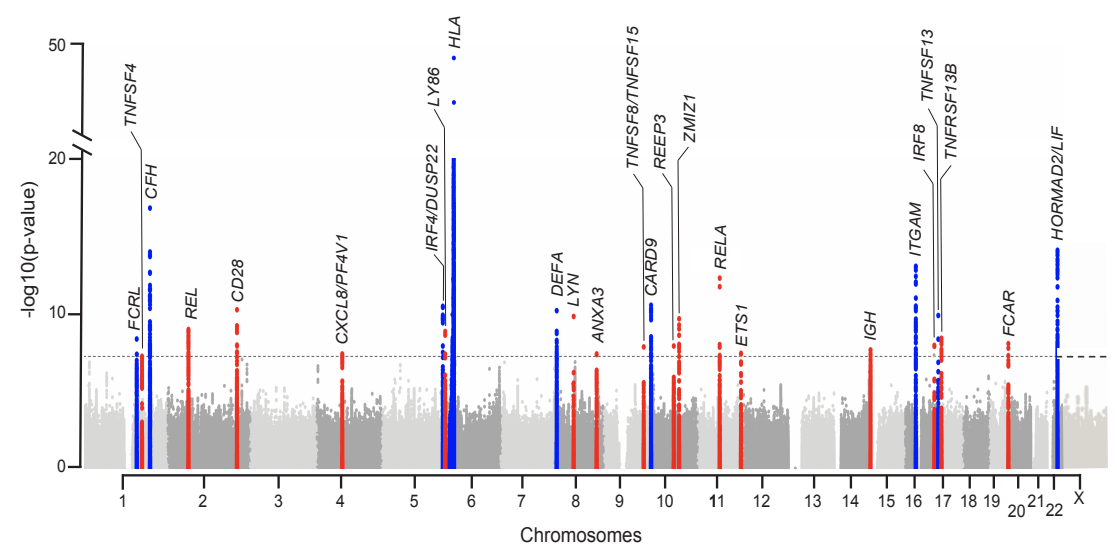

C

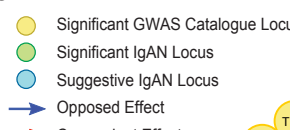

$\rightarrow$ Opposed Effect

$\rightarrow$ Concordant Effect

18

19

20

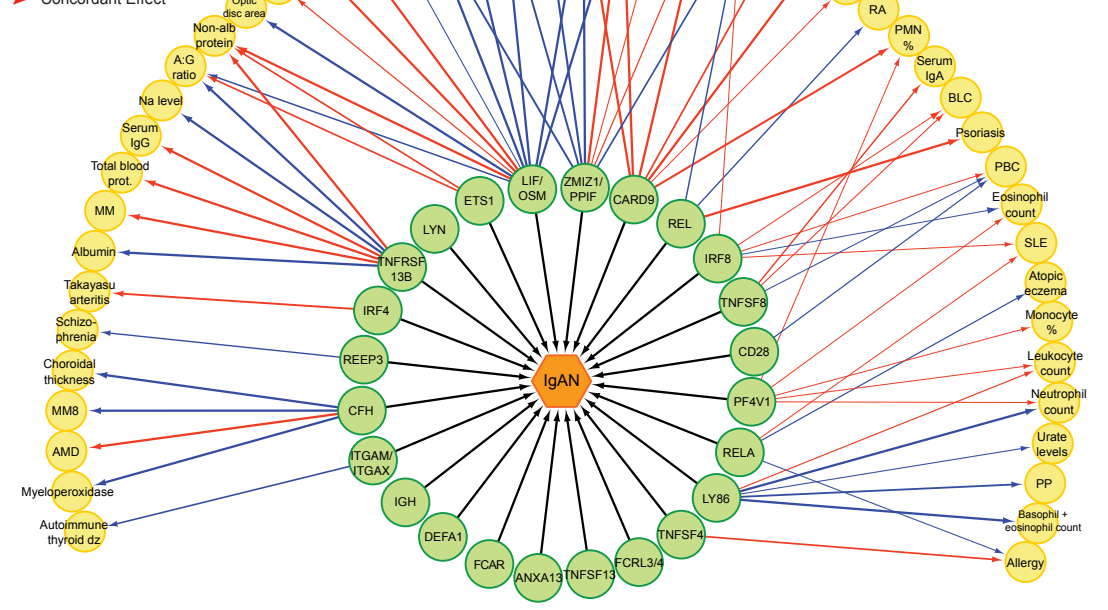

b

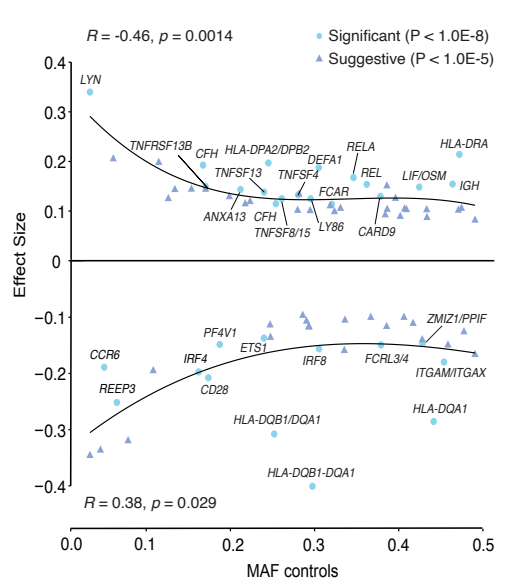

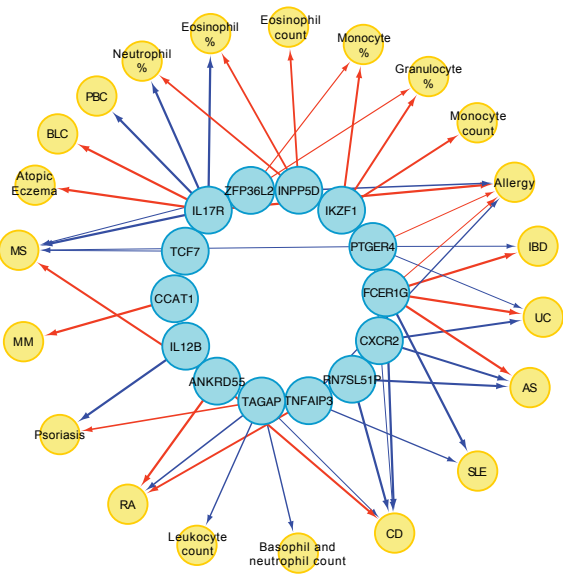


medRxiv preprint doi: https://doi.org/10.1101/2021.11.19.21265383; this version posted November 20, 2021. The copyright holder for this preprint (which was not certified by peer review) is the author/funder, who has granted medRxiv a license to display the preprint in perpetuity.

It is made available under a CC-BY-NC-ND 4.0 International license .

Figure 2. Genome-wide genetic correlation analysis between IgA nephropathy and other complex traits (a) including HLA region and (b) excluding HLA region. The traits are organized by immune-mediated (blue), infectious (green), and cardiometabolic (orange) categories and sorted based on the genetic correlation coefficient ( $\mathrm{rg}$ ); point estimates are provided with their $95 \%$ confidence intervals. PSC: primary sclerosing cholangitis, MN: membranous nephropathy, SLE: systemic lupus erythematosus, CD: Crohn's disease, IBD: inflammatory bowel disease, MS: multiple sclerosis, UC: ulcerative colitis, T1D: type 1 diabetes, AS: ankylosing spondylitis, RA: rheumatoid arthritis, Chol: total serum cholesterol levels, TG: total serum triglycerides levels, LDL: low-density lipoprotein levels, BUN: blood urea nitrogen, eGFR Cr: estimated glomerular filtration rate using serum creatinine levels, T2D: type 2 diabetes, BMI: body mass index, eGFR Cystatin: estimated glomerular filtration rate using serum cystatin levels, HTN: essential hypertension, FEV1/FVC: forced expiration volume at 1 second over forced vital capacity, CAD: coronary artery disease. ${ }^{*}$ phenotypic correlations at $\mathrm{P}<0.05$.

a

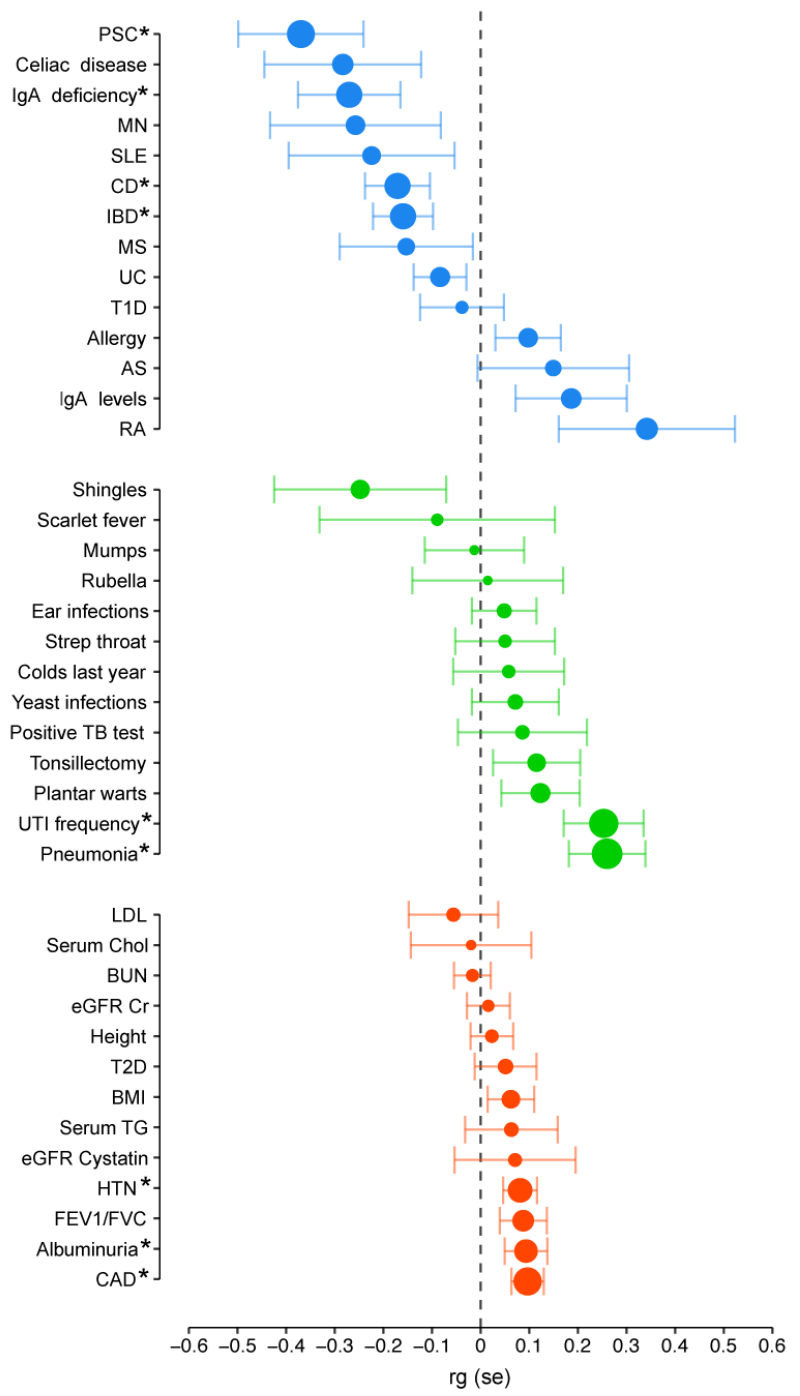

b

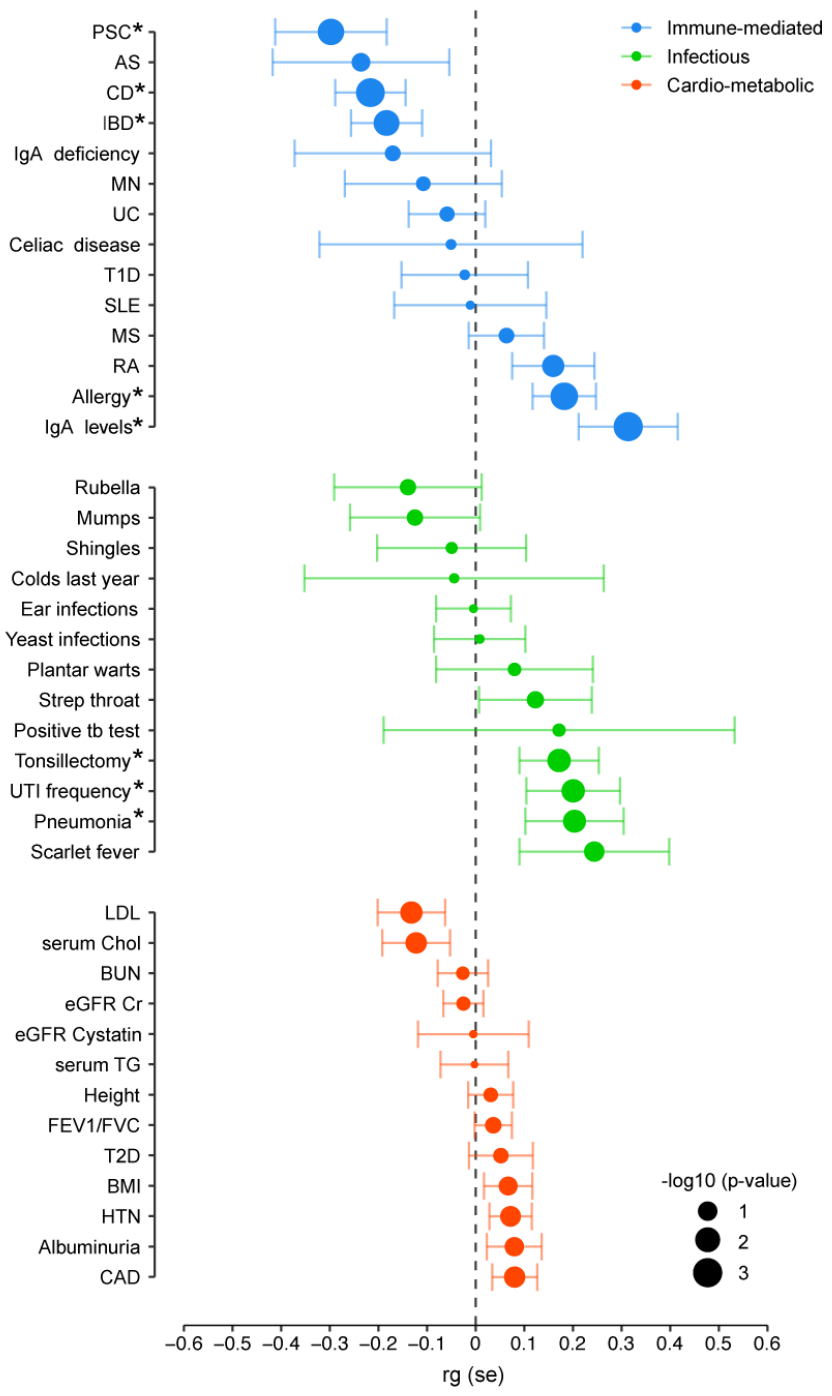


medRxiv preprint doi: https://doi.org/10.1101/2021.11.19.21265383; this version posted November 20, 2021. The copyright holder for this preprint (which was not certified by peer review) is the author/funder, who has granted medRxiv a license to display the preprint in perpetuity.

It is made available under a CC-BY-NC-ND 4.0 International license .

Figure 3. Global pathway, cell type, and tissue enrichment analyses: (a) KEGG, REACTOME and BIOCARTA pathway enrichment map based on the gene set defined by genome-wide significant IgA nephropathy loci after excluding HLA region; the top 10 most significantly enriched pathways and their intersecting GWAS genes are shown; a node size reflects -log10transformed P-values of the multiple-testing adjusted hypergeometric enrichment test in GSEA. (b) Cell type-specific heritability enrichment for functional annotations based on FUN-LDA scoring system for all ENCODE and Roadmap Epigenomics cell types and tissues; the histogram shows the results of partitioned heritability by cell type-specific FUN-LDA functional annotations; only significant results grouped by the tissue type are depicted; a solid red line represents the Bonferroni-corrected $-\log 10$ of the $p$ value threshold of significance $\left(P=3.9 \times 10^{-4}\right)$; a dotted black line represents the -log10 of the nominal $p$-value of 0.05 ; the most significant heritability enrichment were found in blood and immune cells and as well as gastrointestinal mucosal tissues. (c) Tissue and cell-type enrichment analysis with DEPICT; only cells and tissues with a false discovery rate $<0.05$ are shown; Y-axis represents the - $\log 10$ of the p-value and $\mathrm{x}$-axis shows the first level MeSH tissue and cell type annotations; the strongest enrichment is observed for blood and immune cells. (d) Global GWAS enrichment in DNase I-hypersensitive sites (DHS) using GARFIELD; radial lines show odds ratios at two GWAS p-values thresholds (T) for all DHS cells and tissues on the outer circle; dots in the inner ring of the outer circle denote significance of GARFIELD enrichment at $T<1.0 \times 10^{-5}$ (outermost) and $T<1.0 \times 10^{-8}$ (innermost) after multiple-testing correction for the number of effective annotations. The dots colored with respect to the tissue cell type tested (the font size of tissue labels reflects the number of cell types from that tissue, only tissues). Similar to FUN-LDA, GWAS results are most enriched in DHS sites in blood and immune cells, and intestinal mucosal tissue.

a

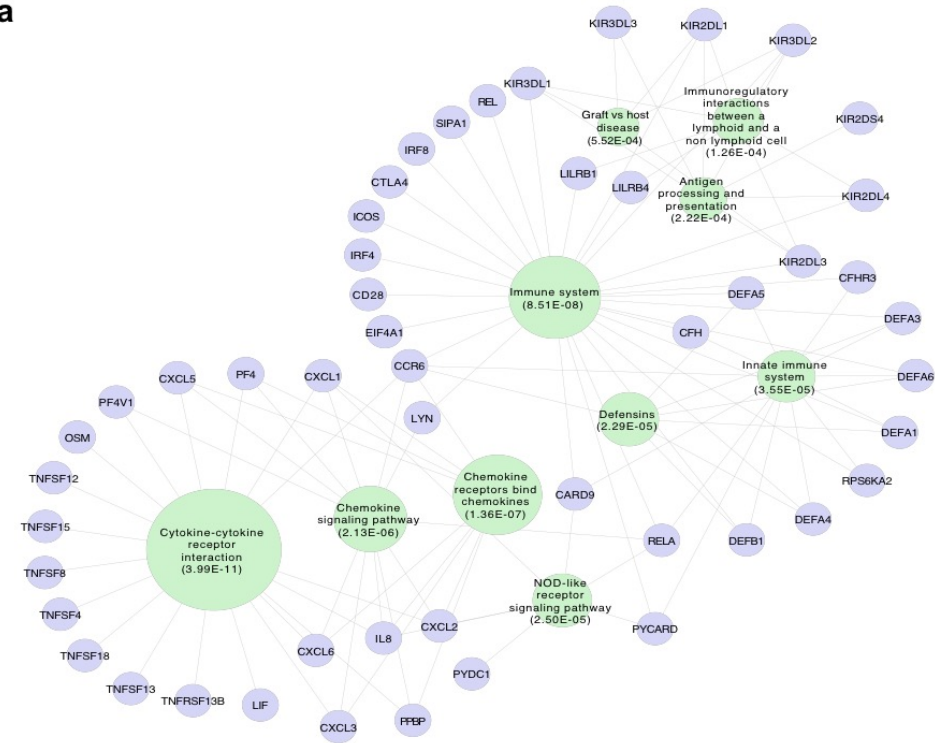

C

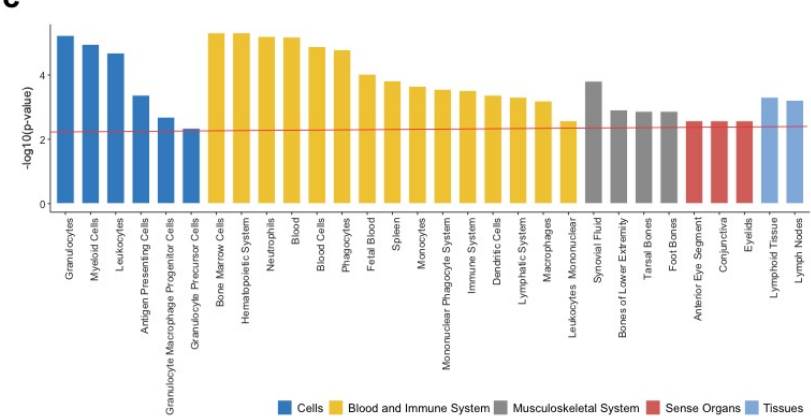

b

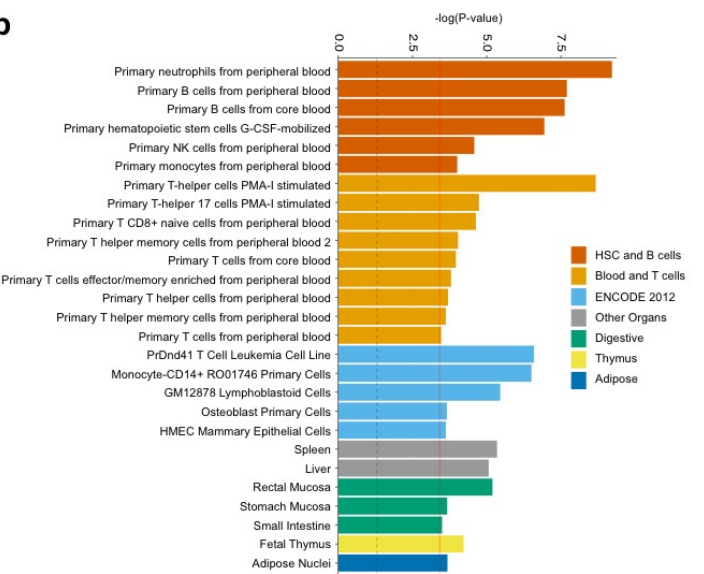

d

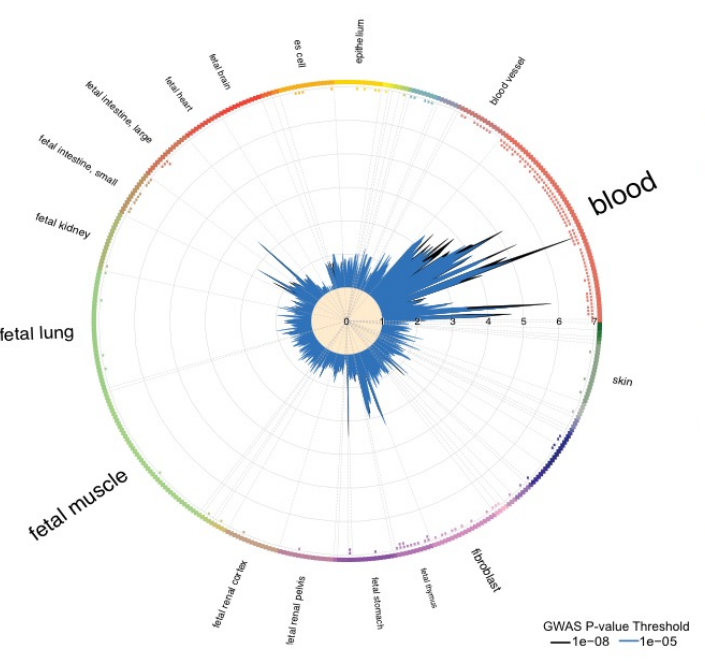

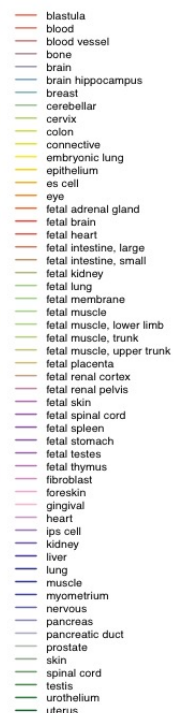


Figure 4. Summary of candidate causal gene prioritizations across IgAN GWAS loci excluding HLA region: (a) cis-eQTL effects in primary immune cells: $x$-axis: 13 immune cell types of the Database of Immune Cell expression QTL epigenomics (DICE) project; posterior probability for a shared causal variant (PP4) is shown for the e-QTL effects that co-localize at PP4>0.50; $y$-axis: significant eGene-eSNP pair with shared GWAS loci depicted by a color bar; *eGenes with detectable blood cis-eQTLs. (b) pQTL effects in blood: IgAN risk alleles or their proxies (yellow nodes) with significant blood pQTLs depicted by blue (reduced protein levels) and red (increased protein levels) nodes; edge thickness corresponds to the LD between the lead pQTL SNP and the top IgAN GWAS SNP at a given locus. (c) Protein-protein interaction (PPI) network for candidate genes at GWAS loci based on InWeb_IM: modules represent genes that are more connected to one another than they are to other genes; each module exhibits a functional enrichment network based on Gene Ontology (GO) biological processes: module 1 represents response to stress and defense response networks (orange), module 2 represents regulation of inflammatory response network (light blue), module 3 represents mRNA splicing via spliceosome network (red), module 4 represents chemokine-mediated signaling pathway network (green), module 5 represents immune response network (purple), module 6 represents cytokine-mediated signaling pathway network (pink), module 7 represents regulation of I-Kappa B kinase/NF-kappaB signaling and apoptotic signaling pathway networks (dark blue) and module 8 represents innate immune response in mucosa and antibacterial humoral response networks (yellow); the gray module has no functional enrichment. Overall, this network has more connectivity than expected by chance (permutation $P<2 e-03$ ). (d) Intersection with transcription factor (TF) ChIP-seq peaks with the significant (top) and suggestive (bottom) IgAN risk loci; $x$-axis: IgAN risk loci; $y$-axis: top significant TFs ranked by the number of intersecting loci; a colored box at the intersection indicates that at a given locus has at least one IgAN-associated variant located within a ChiP-seq peak for the given TF; Datasets were considered significant if their RELI corrected p-values were less than 1E-04; TFs binding to EBNA2 super-enhancers colored in red; ChiP-seq dataset cell type indicated in parentheses; related cell lines for a given TF (e.g., GM12878 and GM12891) were merged for clarity.

a

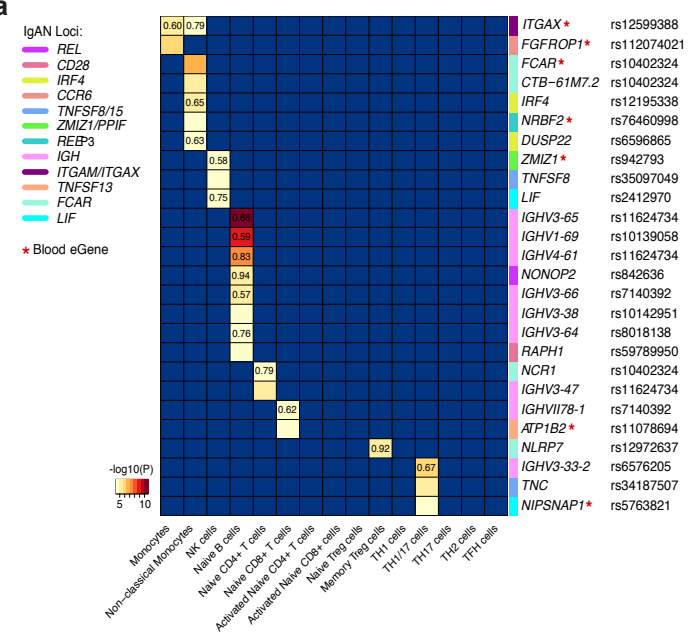

c

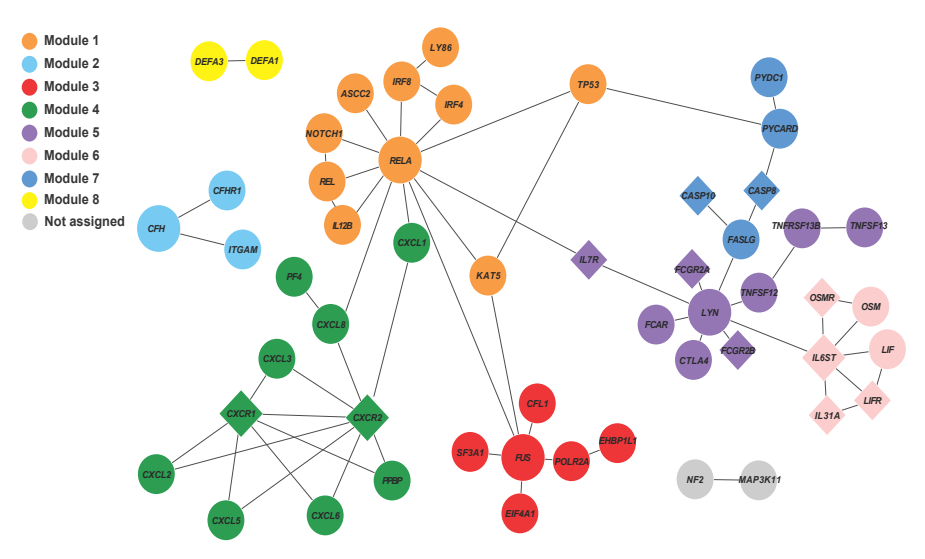

b

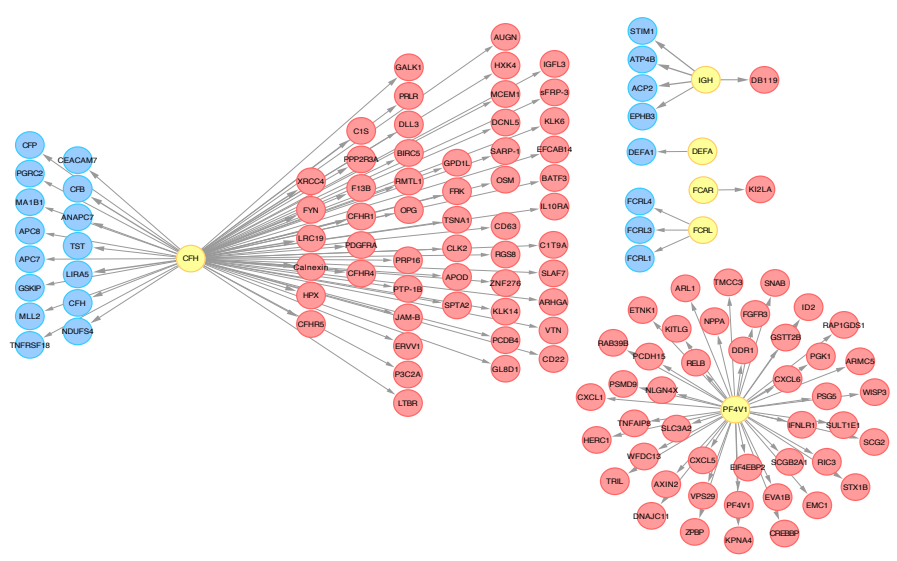

d
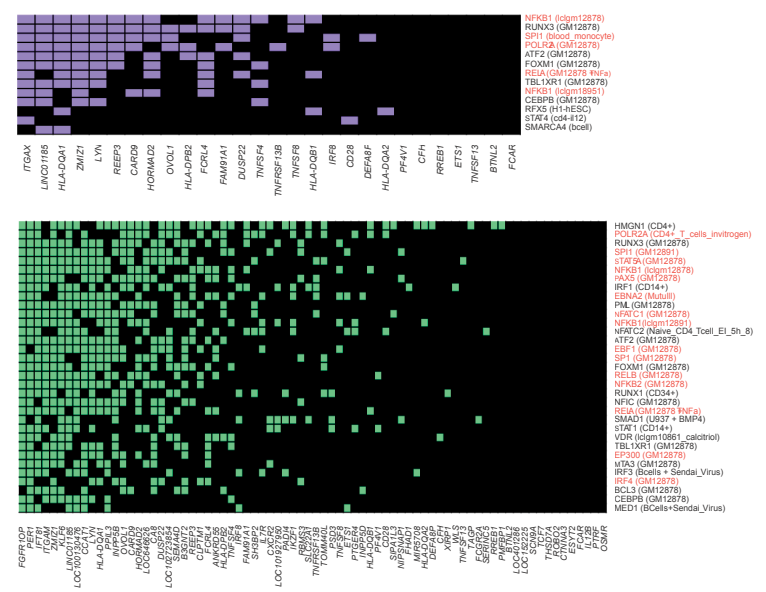
medRxiv preprint doi: https://doi.org/10.1101/2021.11.19.21265383; this version posted November 20, 2021. The copyright holder for this preprint (which was not certified by peer review) is the author/funder, who has granted medRxiv a license to display the preprint in perpetuity.

It is made available under a CC-BY-NC-ND 4.0 International license .

Figure 5. Prioritization of candidate genes at non-HLA loci: blue boxes indicate prioritization criteria based on genomic coordinates (the nearest gene to the index SNP, exonic variant in LD with the top SNP, or top signal intersecting chromatin interaction site with the gene promoter); red boxes indicate the presence of additional functional criteria (any GTEx eQTL effect, blood and immune cell eQTL co-localization, pQTL effects, PPI network connectivity, shared mouse KO phenotype, shared pathways by MAGMA, prioritized by DEPICT, and prioritized by manual PubMed review). The priority score represents a sum of the 13 scoring criteria depicted in blue and red. The genes with the maximum score at each locus (green boxes) were defined as 'biological candidate genes'. Additional annotation indicates drug target genes (yellow boxes). Only 56 of 311 positional candidate 18 genes with a score $>3$ are depicted.

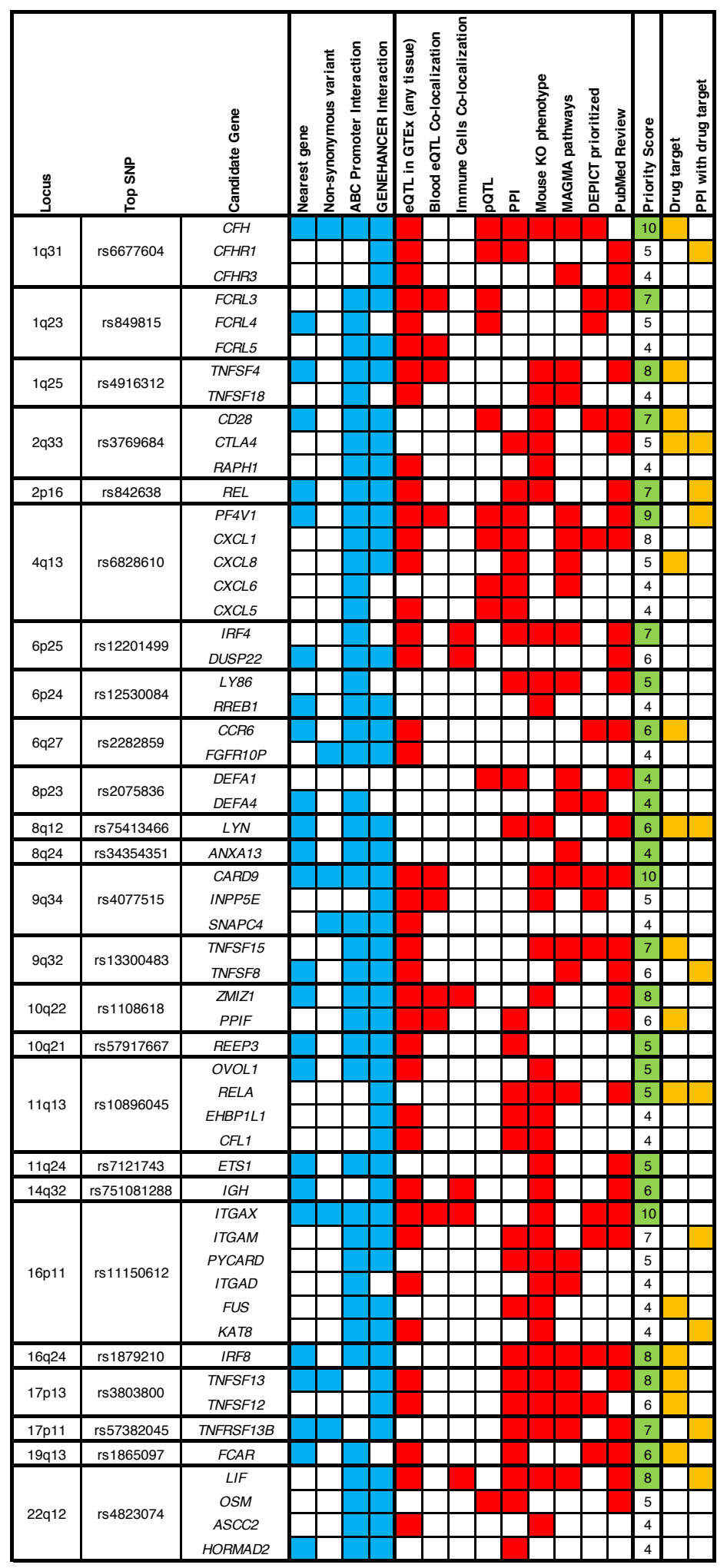


medRxiv preprint doi: https://doi.org/10.1101/2021.11.19.21265383; this version posted November 20, 2021. The copyright holder for this preprint (which was not certified by peer review) is the author/funder, who has granted medRxiv a license to display the preprint in perpetuity.

It is made available under a CC-BY-NC-ND 4.0 International license .

Figure 6: Drug targets among candidate causal genes. IgAN risk alleles (green), prioritized positional candidate genes (gray), related genes in PPI (e.g. ligands/receptors) or same pathway (yellow), targeting drugs approved or currently in clinical trials including agonists and antagonists (blue), and diseases targeted by these drugs (orange); high priority targets defined in Figure 5 are indicated by an asterisk; GWAS loci with candidate causal genes not targeted by the existing drugs are not depicted.

Risk Allele

Candidate Target

Related Targets

Targeting Drugs

Current Indications

\begin{tabular}{|c|c|c|c|c|}
\hline & & & $\mathrm{TT}-30$ & Autoimmune diabetes, $\mathrm{PNH}$ \\
\hline \multirow{6}{*}{ rs6677604-G (1q31) } & & C3 & APL-2, POT-4, AMY-101 & AMD, PNH, C3GN, IgAN, allograft rejection, periodontitis \\
\hline & $\mathrm{CFH}^{*}$ & & Eculizumab, Ravulizumab & AMD, PNH, aHUS, C3GN, allograft rejection, COVID-19 \\
\hline & & C5 & Cemdisiran & PNH, IgA nephropathy \\
\hline & & CFB & Iptacopan, IONIS-FB-LRX & PNH, C3GN, DD, aHUS, IgA nephropathy \\
\hline & & CFD & Danicopan, ALXN2050 & PNH, C3GN, DDD, MPGN, IgA nephropathy \\
\hline & & & Oxelumab & Allergic asthma, allergic rhinitis \\
\hline \multirow[t]{2}{*}{ rs4916312-A (1q25) } & TNFSF4* $(0 X 40 \mathrm{~L})$ & TNFRSF4 $(0 \times 40)$ & KHK4083, ISB-830 & Atopic dermatitis, ulcerative colitis, SLE \\
\hline & & ( & Vonlerolizumab & Solid tumors \\
\hline \multirow{3}{*}{ rs3769684-T (2q33) } & & & Belatacept & Kidney transplant rejection \\
\hline & 管 & 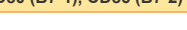 & Abatacept & Rheumatoid arthritis \\
\hline & & & ALPN-101 & Inflammatory Bowel Disease \\
\hline \multirow[t]{2}{*}{ rs842638-T (2p16) } & REL* (C-Rel) & & IT-603, IT-901 & Allograft rejection, GVHD \\
\hline & PF4V1* (CXCL4V1) & CXCR4 & Plerixafor & Hematologic malignancies pre-SCTx \\
\hline \multirow[t]{4}{*}{ rs6828610-G (4q13) } & & & ABX-IL8, HUMAX-IL8 & Melanoma, T1D, chronic bronchitis, COVID-19 \\
\hline & CXCL8 (IL8) & CXCR2 (IL8R) & Troxipide & Gastritis, peptic ulcer disease \\
\hline & CXCLO (ILO) & CXCKL (ILOKK) & Clotrimazole & Fungal infections \\
\hline & & CXCR1, CXCR2 & Reparixin, Navarixin & T1D, asthma, COPD, ulcerative colitis \\
\hline \multirow[t]{2}{*}{ rs2282859-C (6q27) } & CCR6* $^{*}$ & CCL20 & PF-07054894 & Inflammatory bowel disease \\
\hline & LYN $^{*}$ & & Bafetinib & Hematologic malignancies, prostate cancer \\
\hline \multirow{2}{*}{ rs75413466-A (8q12) } & & SRC tyrosine kinases & Dasatinib, Bosutinib & Chronic Myelogenous Leukaemia \\
\hline & 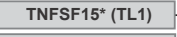 & TNFRSF25, TNFRSF21 & PF-06480605, PR-200 & Inflammatory Bowel Disease \\
\hline rs13300483-T (9q32) & TNFSF8 (CD30L) & TNFRSF8 (CD30) & Brentuximab vedotin & Hematologic Malignancies \\
\hline \multirow[t]{2}{*}{ rs1108618-X (6q27) } & PPIF (CypD) & & Cyclosporine A & Inflammatory Bowel Disease \\
\hline & RELA* (p65) & & Bardoxolone methyl & IgAN, Alport's, FSGS. ADPKD, Diabetic Nephropathy \\
\hline \multirow{2}{*}{ rs10896045-A (11q13) } & KLLA (POS) & NRF2 & Tecfidera & AMD, Non-Hodgkin's Lymphoma \\
\hline & TNFSF12 (TWEAK) & TNFRSF12A & BIIB-023 & Rheumatoid Arthritis, Lupus Nephritis \\
\hline \multirow{2}{*}{ rs3803800-A (17p13) } & TNFSF13* (APRIL) & TNFRSF13B* $($ TACI) & Atacicept & Autoimmune Diseases, IgAN \\
\hline & & & BION1301, VIS649 & IgAN \\
\hline rs57382045-A (17p11) & TNFRSF13B* (TACI) & TNFSF13B (BLYS) & Belimumab, Blisibimod & SLE, Lupus Nephritis, IgAN \\
\hline rs1865097-A (19q13) & FCAR $^{*}$ (CD89) & & MDX-214 & Cancer \\
\hline rs48230748-G (22q12) & LIF $^{*}$ & LIFR & Emfilermin & Infertility \\
\hline
\end{tabular}


medRxiv preprint doi: https://doi.org/10.1101/2021.11.19.21265383; this version posted November 20, 2021. The copyright holder for this preprint (which was not certified by peer review) is the author/funder, who has granted medRxiv a license to display the preprint in perpetuity.

It is made available under a CC-BY-NC-ND 4.0 International license .

Figure 7. Clinical associations of the genome-wide polygenic risk score (GPS) for IgA nephropathy. (a) Survival analysis of a lifetime risk of kidney failure for IgAN cases in the top $90^{\text {th }}$ percentile of the GPS distribution ( $N=2,879$ cases with follow up data). The x-axis shows age starting from 18 years, the $y$-axis shows survival probability without kidney failure with the number of participants at risk at each age cut-off of 20,40,60, and 80 years depicted below; HR: hazard ratio ( $95 \%$ confidence interval) of kidney failure adjusted for sex, site, and ancestry. (b) Phenome-wide association study (PheWAS) for the GPS, including (c) the GPS without the HLA region, based on joint meta-analysis of eMERGE-III $(N=102,138)$ and UKBB $(N=488,377)$ datasets. The $x-$ axis indicates electronic health record phenotypes (phecodes) grouped by system and sorted by significance. The y-axis indicates the level of statistical significance expressed as - $\log (P$-value). An upward triangle indicates a positive association (increased risk) and a downward triangle indicates a negative association (decreased risk) with increasing GPS. Dotted horizontal line represents the significance threshold after Bonferroni correction for the number of phenotypes; significant associations are labeled.

a

Kidney Failure Risk for Top $10 \%$ GPS vs. Others $H R=1.48(1.22-1.79), P=6.55 E-05$
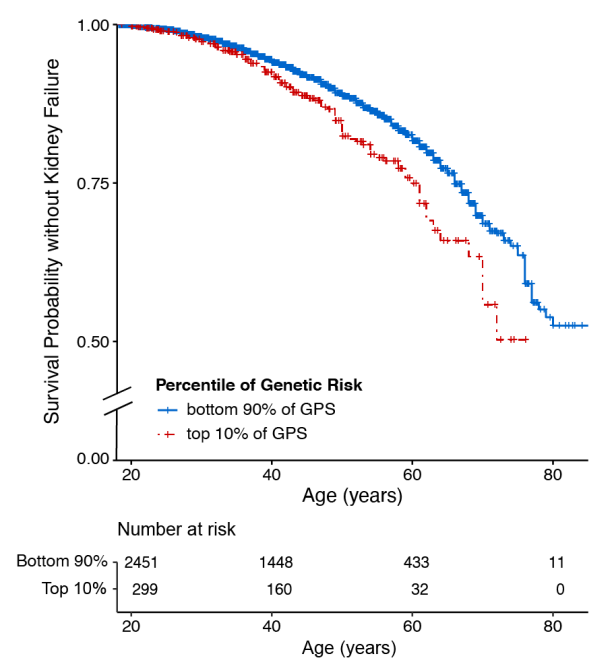

b

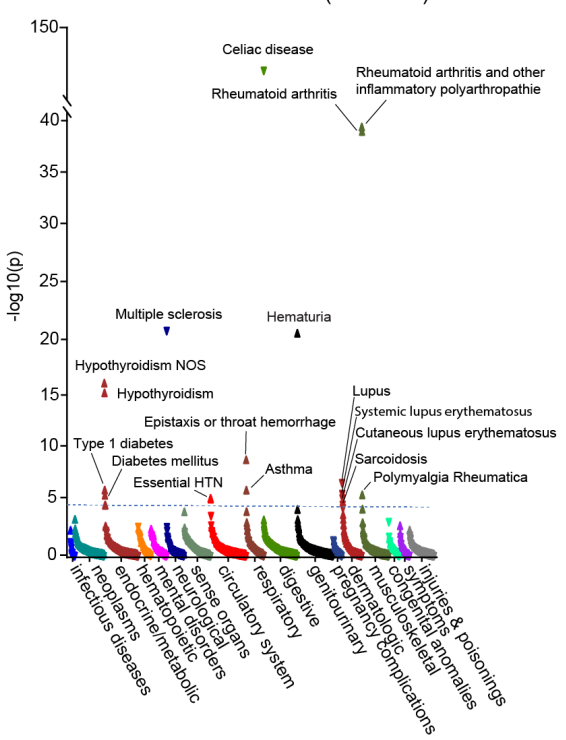

c

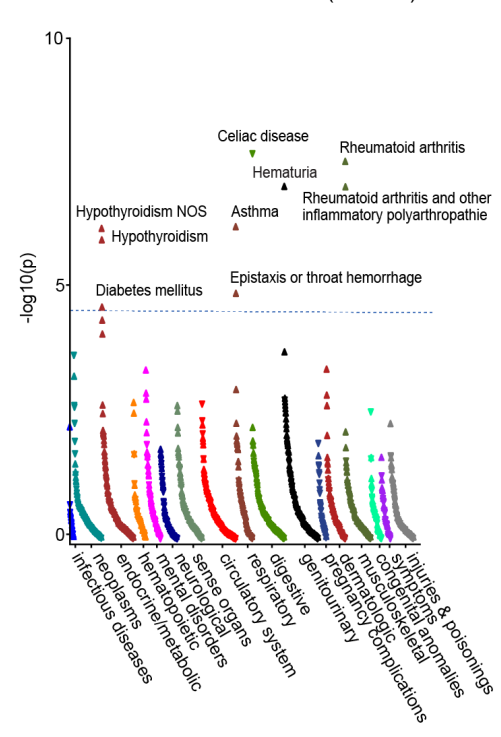


medRxiv preprint doi: https://doi.org/10.1101/2021.11.19.21265383; this version posted November 20, 2021. The copyright holder for this preprint (which was not certified by peer review) is the author/funder, who has granted medRxiv a license to display the preprint in perpetuity.

It is made available under a CC-BY-NC-ND 4.0 International license .

\section{References:}

1 Feehally, J. et al. HLA has strongest association with IgA nephropathy in genome-wide analysis. Journal of the American Society of Nephrology : JASN 21, 1791-1797, doi:10.1681/ASN.2010010076 (2010).

2 Gharavi, A. G. et al. Genome-wide association study identifies susceptibility loci for IgA nephropathy. Nat Genet 43, 321-327, doi:10.1038/ng.787 (2011).

3 Kiryluk, K. et al. Geographic differences in genetic susceptibility to IgA nephropathy: GWAS replication study and geospatial risk analysis. PLoS Genet 8, e1002765, doi:10.1371/journal.pgen.1002765 (2012).

$4 \quad$ Kiryluk, K. et al. Discovery of new risk loci for IgA nephropathy implicates genes involved in immunity against intestinal pathogens. Nature genetics 46, 1187-1196, doi:10.1038/ng.3118 (2014).

5 Yu, X. Q. et al. A genome-wide association study in Han Chinese identifies multiple susceptibility loci for IgA nephropathy. Nature genetics 44, 178-182, doi:10.1038/ng.1047 (2012).

$6 \mathrm{Li}, \mathrm{M}$. et al. Identification of new susceptibility loci for IgA nephropathy in Han Chinese. Nature communications 6, 7270, doi:10.1038/ncomms8270 (2015).

$7 \quad$ Li, M. et al. Genome-Wide Meta-Analysis Identifies Three Novel Susceptibility Loci and Reveals Ethnic Heterogeneity of Genetic Susceptibility for IgA Nephropathy. J Am Soc Nephrol 31, 29492963, doi:10.1681/ASN.2019080799 (2020).

8 Kiryluk, K., Novak, J. \& Gharavi, A. G. Pathogenesis of immunoglobulin A nephropathy: recent insight from genetic studies. Annu Rev Med 64, 339-356, doi:10.1146/annurev-med-041811142014 (2013).

9 Kiryluk, K. \& Novak, J. The genetics and immunobiology of IgA nephropathy. J Clin Invest 124, 2325-2332, doi:10.1172/JCI74475 (2014).

10 Bulik-Sullivan, B. K. et al. LD Score regression distinguishes confounding from polygenicity in genome-wide association studies. Nat Genet 47, 291-295, doi:10.1038/ng.3211 (2015).

11 Feriozzi, S. \& Polci, R. The role of tonsillectomy in IgA nephropathy. J Nephrol 29, 13-19, doi:10.1007/s40620-015-0247-4 (2016).

12 de Leeuw, C. A., Mooij, J. M., Heskes, T. \& Posthuma, D. MAGMA: generalized gene-set analysis of GWAS data. PLoS Comput Biol 11, e1004219, doi:10.1371/journal.pcbi.1004219 (2015).

13 Backenroth, D. et al. FUN-LDA: A Latent Dirichlet Allocation Model for Predicting Tissue-Specific Functional Effects of Noncoding Variation: Methods and Applications. Am J Hum Genet 102, 920942, doi:10.1016/j.ajhg.2018.03.026 (2018).

14 Pers, T. H. et al. Biological interpretation of genome-wide association studies using predicted gene functions. Nat Commun 6, 5890, doi:10.1038/ncomms6890 (2015).

15 lotchkova, V. et al. GARFIELD classifies disease-relevant genomic features through integration of functional annotations with association signals. Nat Genet 51, 343-353, doi:10.1038/s41588-0180322-6 (2019).

16 Harley, J. B. et al. Transcription factors operate across disease loci, with EBNA2 implicated in autoimmunity. Nat Genet 50, 699-707, doi:10.1038/s41588-018-0102-3 (2018).

17 Zhou, H. et al. Epstein-Barr virus oncoprotein super-enhancers control B cell growth. Cell Host Microbe 17, 205-216, doi:10.1016/j.chom.2014.12.013 (2015).

18 Sugai, M., Watanabe, K., Nambu, Y., Hayashi, T. \& Shimizu, A. Functions of Runx in IgA class switch recombination. J Cell Biochem 112, 409-414, doi:10.1002/jcb.22971 (2011). 
19 Malhotra, N. \& Kang, J. SMAD regulatory networks construct a balanced immune system. Immunology 139, 1-10, doi:10.1111/imm.12076 (2013).

20 Lage, K. et al. A human phenome-interactome network of protein complexes implicated in genetic disorders. Nat Biotechnol 25, 309-316, doi:10.1038/nbt1295 (2007).

21 Warde-Farley, D. et al. The GeneMANIA prediction server: biological network integration for gene prioritization and predicting gene function. Nucleic Acids Res 38, W214-220, doi:10.1093/nar/gkq537 (2010).

22 Han, S. S. et al. The Role of TNF Superfamily Member 13 in the Progression of IgA Nephropathy. J Am Soc Nephrol 27, 3430-3439, doi:10.1681/ASN.2015060677 (2016).

23 Yamada, K. et al. Leukemia Inhibitory Factor Signaling Enhances Production of GalactoseDeficient IgA1 in IgA Nephropathy. Kidney Dis (Basel) 6, 168-180, doi:10.1159/000505748 (2020). 24 Suzuki, H. et al. Cytokines alter IgA1 O-glycosylation by dysregulating C1GalT1 and ST6GalNAc-II enzymes. J Biol Chem 289, 5330-5339, doi:10.1074/jbc.M113.512277 (2014).

25 Yamada, K. et al. Inhibition of STAT3 Signaling Reduces IgA1 Autoantigen Production in IgA Nephropathy. Kidney Int Rep 2, 1194-1207, doi:10.1016/j.ekir.2017.07.002 (2017).

26 Vosa, U. et al. Large-scale cis- and trans-eQTL analyses identify thousands of genetic loci and polygenic scores that regulate blood gene expression. Nat Genet 53, 1300-1310, doi:10.1038/s41588-021-00913-z (2021).

27 Owen, C. R., Yuan, L. \& Basson, M. D. Smad3 knockout mice exhibit impaired intestinal mucosal healing. Lab Invest 88, 1101-1109, doi:10.1038/labinvest.2008.77 (2008).

28 Yang, X. et al. Targeted disruption of SMAD3 results in impaired mucosal immunity and diminished T cell responsiveness to TGF-beta. EMBO J 18, 1280-1291, doi:10.1093/emboj/18.5.1280 (1999).

29 Agarwal, S. et al. Human Fc Receptor-like 3 Inhibits Regulatory T Cell Function and Binds Secretory IgA. Cell Rep 30, 1292-1299 e1293, doi:10.1016/j.celrep.2019.12.099 (2020).

30 Tolnay, M. Lymphocytes sense antibodies through human FCRL proteins: Emerging roles in mucosal immunity. J Leukoc Biol, doi:10.1002/JLB.4RU0221-102RR (2021).

31 Choobdar, S. et al. Assessment of network module identification across complex diseases. Nat Methods 16, 843-852, doi:10.1038/s41592-019-0509-5 (2019).

32 Zhang, X. et al. An integrative investigation of the therapeutic mechanism of Ainsliaea fragrans Champ. in cervicitis using liquid chromatography tandem mass spectrometry based on a rat plasma metabolomics strategy. J Pharm Biomed Anal 156, 221-231, doi:10.1016/j.jpba.2018.04.048 (2018).

33 Zhao, L. et al. Stachydrine ameliorates isoproterenol-induced cardiac hypertrophy and fibrosis by suppressing inflammation and oxidative stress through inhibiting NF-kappaB and JAK/STAT signaling pathways in rats. Int Immunopharmacol 48, 102-109, doi:10.1016/j.intimp.2017.05.002 (2017).

34 Fulco, C. P. et al. Activity-by-contact model of enhancer-promoter regulation from thousands of CRISPR perturbations. Nat Genet 51, 1664-1669, doi:10.1038/s41588-019-0538-0 (2019).

35 Fishilevich, S. et al. GeneHancer: genome-wide integration of enhancers and target genes in GeneCards. Database (Oxford) 2017, doi:10.1093/database/bax028 (2017).

36 Zipfel, P. F. et al. Complement Inhibitors in Clinical Trials for Glomerular Diseases. Front Immunol 10, 2166, doi:10.3389/fimmu.2019.02166 (2019).

37 Titze, S. et al. Disease burden and risk profile in referred patients with moderate chronic kidney disease: composition of the German Chronic Kidney Disease (GCKD) cohort. Nephrol Dial Transplant 30, 441-451, doi:10.1093/ndt/gfu294 (2015). 
Wunnenburger, S. et al. Associations between genetic risk variants for kidney diseases and kidney disease etiology. Sci Rep 7, 13944, doi:10.1038/s41598-017-13356-6 (2017).

39 Hansen, I. S., Baeten, D. L. P. \& den Dunnen, J. The inflammatory function of human IgA. Cell Mol Life Sci 76, 1041-1055, doi:10.1007/s00018-018-2976-8 (2019).

40 Infante, B. et al. Recurrence of immunoglobulin A nephropathy after kidney transplantation: a narrative review of the incidence, risk factors, pathophysiology and management of immunosuppressive therapy. Clin Kidney J 13, 758-767, doi:10.1093/ckj/sfaa060 (2020).

41 Nelson, M. R. et al. The support of human genetic evidence for approved drug indications. Nat Genet 47, 856-860, doi:10.1038/ng.3314 (2015).

42 Chang, C. C. et al. Second-generation PLINK: rising to the challenge of larger and richer datasets. Gigascience 4, 7, doi:10.1186/s13742-015-0047-8 (2015).

43 Willer, C. J., Li, Y. \& Abecasis, G. R. METAL: fast and efficient meta-analysis of genomewide association scans. Bioinformatics 26, 2190-2191, doi:10.1093/bioinformatics/btq340 (2010).

44 Yang, J. et al. Conditional and joint multiple-SNP analysis of GWAS summary statistics identifies additional variants influencing complex traits. Nat Genet 44, 369-375, S361-363, doi:10.1038/ng.2213 (2012).

45 Yang, J., Lee, S. H., Goddard, M. E. \& Visscher, P. M. GCTA: a tool for genome-wide complex trait analysis. Am J Hum Genet 88, 76-82, doi:10.1016/j.ajhg.2010.11.011 (2011).

46 Jia, X. et al. Imputing amino acid polymorphisms in human leukocyte antigens. PLoS One 8, e64683, doi:10.1371/journal.pone.0064683 (2013).

47 Pillai, N. E. et al. Predicting HLA alleles from high-resolution SNP data in three Southeast Asian populations. Hum Mol Genet 23, 4443-4451, doi:10.1093/hmg/ddu149 (2014).

48 Genomes Project, C. et al. An integrated map of genetic variation from 1,092 human genomes. Nature 491, 56-65, doi:10.1038/nature11632 (2012).

49 Tian, C. et al. Genome-wide association and HLA region fine-mapping studies identify susceptibility loci for multiple common infections. Nat Commun 8, 599, doi:10.1038/s41467-01700257-5 (2017).

50 Vilhjalmsson, B. J. et al. Modeling Linkage Disequilibrium Increases Accuracy of Polygenic Risk Scores. Am J Hum Genet 97, 576-592, doi:10.1016/j.ajhg.2015.09.001 (2015).

51 Khera, A. V. et al. Polygenic Prediction of Weight and Obesity Trajectories from Birth to Adulthood. Cell 177, 587-596 e589, doi:10.1016/j.cell.2019.03.028 (2019).

52 Khera, A. V. et al. Genome-wide polygenic scores for common diseases identify individuals with risk equivalent to monogenic mutations. Nat Genet 50, 1219-1224, doi:10.1038/s41588-0180183-z (2018).

53 Gorski, M. et al. 1000 Genomes-based meta-analysis identifies 10 novel loci for kidney function. Sci Rep 7, 45040, doi:10.1038/srep45040 (2017).

54 Pattaro, C. et al. Genetic associations at 53 loci highlight cell types and biological pathways relevant for kidney function. Nat Commun 7, 10023, doi:10.1038/ncomms10023 (2016).

55 Finucane, H. K. et al. Partitioning heritability by functional annotation using genome-wide association summary statistics. Nat Genet 47, 1228-1235, doi:10.1038/ng.3404 (2015).

56 Roadmap Epigenomics, C. et al. Integrative analysis of 111 reference human epigenomes. Nature 518, 317-330, doi:10.1038/nature14248 (2015).

57 Heng, T. S., Painter, M. W. \& Immunological Genome Project, C. The Immunological Genome Project: networks of gene expression in immune cells. Nat Immunol 9, 1091-1094, doi:10.1038/ni1008-1091 (2008).

58 Eppig, J. T. et al. The Mouse Genome Database (MGD): facilitating mouse as a model for human biology and disease. Nucleic Acids Res 43, D726-736, doi:10.1093/nar/gku967 (2015). 
medRxiv preprint doi: https://doi.org/10.1101/2021.11.19.21265383; this version posted November 20, 2021. The copyright holder for this

preprint (which was not certified by peer review) is the author/funder, who has granted medRxiv a license to display the preprint in perpetuity.

It is made available under a CC-BY-NC-ND 4.0 International license .

59 Bult, C. J. et al. Mouse genome database 2016. Nucleic Acids Res 44, D840-847, doi:10.1093/nar/gkv1211 (2016).

60 Hormozdiari, F., Kostem, E., Kang, E. Y., Pasaniuc, B. \& Eskin, E. Identifying causal variants at loci with multiple signals of association. Genetics 198, 497-508, doi:10.1534/genetics.114.167908 (2014).

61 Schmiedel, B. J. et al. Impact of Genetic Polymorphisms on Human Immune Cell Gene Expression. Cell 175, 1701-1715 e1716, doi:10.1016/j.cell.2018.10.022 (2018).

62 Consortium, G. T. The Genotype-Tissue Expression (GTEx) project. Nat Genet 45, 580-585, doi:10.1038/ng.2653 (2013).

63 Qiu, C. et al. Renal compartment-specific genetic variation analyses identify new pathways in chronic kidney disease. Nat Med 24, 1721-1731, doi:10.1038/s41591-018-0194-4 (2018).

64 Suhre, K. et al. Human metabolic individuality in biomedical and pharmaceutical research. Nature 477, 54-60, doi:10.1038/nature10354 (2011).

65 Shin, S. Y. et al. An atlas of genetic influences on human blood metabolites. Nat Genet 46, 543550, doi:10.1038/ng.2982 (2014).

66 Sun, B. B. et al. Genomic atlas of the human plasma proteome. Nature 558, 73-79, doi:10.1038/s41586-018-0175-2 (2018).

67 Suhre, K. et al. Connecting genetic risk to disease end points through the human blood plasma proteome. Nat Commun 8, 14357, doi:10.1038/ncomms14357 (2017).

68 Emilsson, V. et al. Co-regulatory networks of human serum proteins link genetics to disease. Science 361, 769-773, doi:10.1126/science.aaq1327 (2018).

69 Giambartolomei, C. et al. Bayesian test for colocalisation between pairs of genetic association studies using summary statistics. PLoS Genet 10, e1004383, doi:10.1371/journal.pgen.1004383 (2014).

$70 \mathrm{Li}, \mathrm{T}$. et al. A scored human protein-protein interaction network to catalyze genomic interpretation. Nat Methods 14, 61-64, doi:10.1038/nmeth.4083 (2017).

71 Su, G., Kuchinsky, A., Morris, J. H., States, D. J. \& Meng, F. GLay: community structure analysis of biological networks. Bioinformatics 26, 3135-3137, doi:10.1093/bioinformatics/btq596 (2010).

72 Nepusz, T., Yu, H. \& Paccanaro, A. Detecting overlapping protein complexes in protein-protein interaction networks. Nat Methods 9, 471-472, doi:10.1038/nmeth.1938 (2012).

73 Shannon, P. et al. Cytoscape: a software environment for integrated models of biomolecular interaction networks. Genome Res 13, 2498-2504, doi:10.1101/gr.1239303 (2003).

74 Szklarczyk, D. et al. STRING v11: protein-protein association networks with increased coverage, supporting functional discovery in genome-wide experimental datasets. Nucleic Acids Res 47, D607-D613, doi:10.1093/nar/gky1131 (2019).

75 Chen, J., Bardes, E. E., Aronow, B. J. \& Jegga, A. G. ToppGene Suite for gene list enrichment analysis and candidate gene prioritization. Nucleic Acids Res 37, W305-311, doi:10.1093/nar/gkp427 (2009).

76 Graeber, T. G. \& Eisenberg, D. Bioinformatic identification of potential autocrine signaling loops in cancers from gene expression profiles. Nat Genet 29, 295-300, doi:10.1038/ng755 (2001).

77 Knox, C. et al. DrugBank 3.0: a comprehensive resource for 'omics' research on drugs. Nucleic Acids Res 39, D1035-1041, doi:10.1093/nar/gkq1126 (2011).

78 Zhu, F. et al. Therapeutic target database update 2012: a resource for facilitating target-oriented drug discovery. Nucleic Acids Res 40, D1128-1136, doi:10.1093/nar/gkr797 (2012).

79 Carvalho-Silva, D. et al. Open Targets Platform: new developments and updates two years on. Nucleic Acids Res 47, D1056-D1065, doi:10.1093/nar/gky1133 (2019). 
medRxiv preprint doi: https://doi.org/10.1101/2021.11.19.21265383; this version posted November 20, 2021. The copyright holder for this

preprint (which was not certified by peer review) is the author/funder, who has granted medRxiv a license to display the preprint in perpetuity.

It is made available under a CC-BY-NC-ND 4.0 International license .

280

Levey, A. S. et al. A new equation to estimate glomerular filtration rate. Ann Intern Med 150, 604612, doi:10.7326/0003-4819-150-9-200905050-00006 (2009).

81 Schwartz, G. J. et al. New equations to estimate GFR in children with CKD. J Am Soc Nephrol 20, 629-637, doi:10.1681/ASN.2008030287 (2009).

82 Stanaway, I. B. et al. The eMERGE genotype set of 83,717 subjects imputed to 40 million variants genome wide and association with the herpes zoster medical record phenotype. Genet Epidemiol 43, 63-81, doi:10.1002/gepi.22167 (2019).

83 Khan, A. et al. Medical Records-Based Genetic Studies of the Complement System. J Am Soc Nephrol 32, 2031-2047, doi:10.1681/ASN.2020091371 (2021).

84 Shang, N. et al. Medical records-based chronic kidney disease phenotype for clinical care and "big data" observational and genetic studies. NPJ Digit Med 4, 70, doi:10.1038/s41746-021-00428-1 (2021).

85 McCarthy, S. et al. A reference panel of 64,976 haplotypes for genotype imputation. Nat Genet 48, 1279-1283, doi:10.1038/ng.3643 (2016).

86 Abraham, G. \& Inouye, M. Fast principal component analysis of large-scale genome-wide data. PLoS One 9, e93766, doi:10.1371/journal.pone.0093766 (2014).

87 Sudlow, C. et al. UK biobank: an open access resource for identifying the causes of a wide range of complex diseases of middle and old age. PLoS Med 12, e1001779, doi:10.1371/journal.pmed.1001779 (2015).

88 Altshuler, D. M. et al. A global reference for human genetic variation. Nature 526, 68-+, doi:10.1038/nature15393 (2015).

89 Howie, B., Fuchsberger, C., Stephens, M., Marchini, J. \& Abecasis, G. R. Fast and accurate genotype imputation in genome-wide association studies through pre-phasing. Nature Genetics 44, 955-+, doi:10.1038/ng.2354 (2012).

90 Bycroft, C. et al. The UK Biobank resource with deep phenotyping and genomic data. Nature 562, 203-+, doi:10.1038/s41586-018-0579-z (2018).

91 Denny, J. C. et al. PheWAS: demonstrating the feasibility of a phenome-wide scan to discover gene-disease associations. Bioinformatics 26, 1205-1210, doi:10.1093/bioinformatics/btq126 (2010). 